\title{
Climatic controls on water vapor deuterium excess in the marine boundary layer of the North Atlantic based on 500 days of in situ, continuous measurements
}

\author{
H. C. Steen-Larsen ${ }^{1,2}$, A. E. Sveinbjörnsdottir ${ }^{3}$, A. J. Peters ${ }^{4}$, V. Masson-Delmotte ${ }^{1}$, M. P. Guishard ${ }^{4}$, G. Hsiao ${ }^{5}$, \\ J. Jouzel ${ }^{1}$, D. Noone ${ }^{2}$, J. K. Warren ${ }^{4}$, and J. W. C. White ${ }^{6}$ \\ ${ }^{1}$ Laboratoire des Sciences du Climat et de l'Environnement, UMR CEA-CNRS-UVSQ/IPSL 8212, Gif-sur-Yvette, France \\ ${ }^{2}$ Department of Atmospheric and Oceanic Sciences, and Cooperative Institute for Research in Environmental Sciences, \\ University of Colorado, Boulder, Colorado, USA \\ ${ }^{3}$ Institute of Earth Sciences, University of Iceland, Reykjavik, Iceland \\ ${ }^{4}$ Bermuda Institute of Ocean Sciences, St. George's GE 01, Bermuda, UK \\ ${ }^{5}$ Picarro Inc., Santa Clara, California, USA \\ ${ }^{6}$ Institute of Arctic and Alpine Research, Campus Box 450, University of Colorado, Boulder, Colorado, USA
}

Correspondence to: H. C. Steen-Larsen (hanschr@gfy.ku.dk)

Received: 6 December 2013 - Published in Atmos. Chem. Phys. Discuss.: 24 January 2014

Revised: 8 May 2014 - Accepted: 4 June 2014 - Published: 4 August 2014

\begin{abstract}
Continuous, in situ measurements of water vapor isotopic composition have been conducted in the North Atlantic, at the Bermuda Islands $\left(32.26^{\circ} \mathrm{N}, 64.88^{\circ} \mathrm{W}\right)$, between November 2011 and June 2013, using a cavity ringdown spectrometer water vapor isotope analyzer and an autonomous self-designed calibration system. Meticulous calibration allows us to reach an accuracy and precision on $10 \mathrm{~min}$ average of $\delta^{18} \mathrm{O}, \delta D$, and d-excess of, $0.14,0.85$, and $1.1 \%$, verified using two parallel instruments with independent calibration. As a result of more than 500 days with 6hourly data the relationships between deuterium excess, relative humidity (RH), sea surface temperature (SST), wind speed, and wind direction are assessed. From the whole data set, $84 \%$ of d-excess variance is explained by a strong linear relationship with relative humidity. The slope of this relationship ( $-42.6 \pm 0.4 \% \% \%(\mathrm{RH}))$ is similar to the theoretical prediction of Merlivat and Jouzel (1979) for SST between 20 and $30^{\circ} \mathrm{C}$. However, in contrast with theory, no effect of wind speed could be detected on the relationship between d-excess and relative humidity. Separating the data set into winter, spring, summer, and autumn seasons reveals different linear relationships between d-excess and humidity. Changes in wind directions are observed to affect the relationships between d-excess and humidity. The observed seasonal variability in the relationship between d-excess and relative hu-
\end{abstract}

midity underlines the importance of long-term monitoring to make accurate conclusions.

\section{Introduction}

Water-stable isotopes in the atmosphere are key tracers of physical processes within the hydrological cycle. Since the 1950s, water-stable isotopes of precipitation and their imprint in many different natural archives have been measured by mass spectrometry and understood in relation to processes controlling evaporation and evapotranspiration, moisture transport, and condensation (Epstein and Mayeda, 1953; Dansgaard, 1954; Rozanski et al., 1993). The founding works of Dansgaard (1964) and Craig and Gordon (1965) have shaped the last $\sim 50 \mathrm{yr}$ of research using water isotopes. The knowledge of hydrological cycle processes is fundamental for the implementation of water-stable isotopes in conceptual Rayleigh distillation models or atmospheric regional or general circulation models, and their various applications such as the quantitative interpretation of ice core records (Johnsen et al., 1989; Jouzel et al., 1997). Here, we will focus on the basis of the atmospheric water cycle: the relation between $\mathrm{H}_{2}^{18} \mathrm{O}$ and $\mathrm{HD}^{16} \mathrm{O}$ compared to $\mathrm{H}_{2}^{16} \mathrm{O}$ in the marine boundary layer near the ocean surface. We will use the delta notation 
introduced by Craig (1961a):

$\delta^{*}=\left(\frac{R_{\text {sample }}}{R_{\text {VSMOW }}}-1\right) \times 1000$,

where $\delta^{*}$ represents either $\delta^{18} \mathrm{O}$ or $\delta D$, and $R_{\text {sample }}$ and $R_{\text {VSMOW }}$ are the isotopic ratio of the sample and the Vienna Standard Mean Ocean Water (VSMOW).

As noted by Craig (1961b), the relationship between $\delta^{18} \mathrm{O}$ and $\delta D$ reflects the imprint of kinetic and equilibrium fractionation processes. The second-order parameter d-excess has been defined by Dansgaard (1964) in order to highlight the isotopic variability, which is not driven by equilibrium fractionation that otherwise for the isotopic values encountered here leads to a linear relationship between $\delta^{18} \mathrm{O}$ and $\delta D$ with a global mean slope of $8(\% \circ / \%$ ) (Majoube, 1971):

$d$ excess $=\delta D-8 \times \delta^{18} \mathrm{O}$.

Without large changes in temperature along the distillation path (which alter the slope of 8 due to the temperature dependence of the equilibrium fractionation coefficients), changes in d-excess are dominated by kinetic fractionation. As qualitatively explained by, e.g., Dansgaard (1964), the kinetic effect during evaporation arises from the different diffusivities of the water isotopes $\mathrm{H}_{2}^{16} \mathrm{O}, \mathrm{HD}^{16} \mathrm{O}$, and $\mathrm{H}_{2}^{18} \mathrm{O}$ in the air. This kinetic fractionation during evaporation was formally described by Merlivat and Jouzel (1979) (hereafter MJ79) under an idealized "closure assumption" implying no advection of moisture. They formulated theoretical relationships between d-excess, sea surface temperature (SST), and relative humidity of the air compared to the saturation vapor pressure at the ocean surface $\left(\mathrm{RH}_{\mathrm{SST}}\right)$. We will in the following refer to $\mathrm{RH}_{\mathrm{SST}}$ as relative humidity at the SST. The relationships were expected to depend on the wind regime affecting molecular and turbulence mixing at the ocean surface, following the evaporation theory of Brutsaert (1975). Assessing the validity of MJ79 calculations requires longterm monitoring of water vapor isotopes in the marine boundary layer in order to separate the effect of the different influencing factors.

During the past decades only a few observations of surface water vapor isotopes have been conducted in the marine boundary layer due to the analytical challenges associated with cryogenic sampling. Gat et al. (2003) conducted cryogenic sampling of water vapor in the eastern Mediterranean and reported high d-excess values, due to strong kinetic effect produced as dry air transported from Europe moved across the warm Mediterranean Sea, a finding further supported by the study of Pfahl and Wernli (2009). Similarly, in another study, high d-excess values measured in several Arctic areas were attributed to high kinetic effect produced by dry polar air at the sea ice margin (Kurita, 2011; Steen-Larsen et al., 2013). Uemura et al. (2008) cryogenically collected 60 samples of water vapor onboard a research vessel during a one-month crossing of the Southern Ocean from Australia to Antarctica and back to South Africa. Consistent with the theory of MJ79, a strong relationship was observed between d-excess and $\mathrm{RH}_{\text {SST }}$ (with a slope of $-58 \% / \% \mathrm{RH}_{\mathrm{SST}}$ ), but the strong correlation between $\mathrm{RH}_{\mathrm{SST}}$ and SST did not allow identifying the independant impact of SST alone. Pfahl and Sodemann (2014) used data from Gat et al. (2003), Pfahl and Wernli (2009), and Uemura et al. (2008) to propose a globally applicable interpretation of d-excess in precipitation based on the overall linear relationship between surface vapor d-excess and RH. Support for the strong relationship between d-excess in the marine boundary layer water vapor and RH was recently obtained from a one-month campaign in the eastern North Atlantic by Benetti et al. (2014) (slope of $-45 \% / \% \mathrm{RH}_{\mathrm{SST}}$ ). The differences between the findings from Uemura et al. (2008) and Bennetti et al. (2014) open questions about both temporal and spatial variability in the relationship between d-excess and $\mathrm{RH}_{\mathrm{SST}}$.

With the availability of commercial laser water vapor isotope analyzers (Crosson et al., 2002; Baer et al., 2002), it has recently become possible to perform accurate and continuous in situ measurements, if correct protocols are implemented for the calibration of the measurements. Further developments have allowed the setup of autonomous systems in remote field sites in regions spanning from Greenland to Niger, producing records of the variability of surface water vapor isotopic composition over seasons to years (e.g., SteenLarsen et al., 2013; Bonne et al., 2014; Tremoy et al., 2012). With the goal of performing year-round measurements of water vapor isotopic composition in the North Atlantic marine boundary layer, we have focused on the Bermuda Islands. The location was chosen due to warm SST as a result of the nearby Gulf Stream current, and because this area is expected to be a key moisture source for the North Atlantic sector. Indeed, part of our motivation was to characterize the isotopic composition at the source of moisture for Greenland and therefore to improve the understanding of the processes governing Greenland water-stable isotopes and the interpretation of d-excess from Greenland ice core records (e.g., Steen-Larsen et al., 2011; Johnsen et al., 1989; Fisher, 1992; Masson-Delmotte et al., 2005; Jouzel et al., 2007). For this purpose, we have designed a water vapor isotope monitoring system with the goal of being completely autonomous for periods of several months and able to perform frequent drift calibrations in order to have high accuracy for the dexcess. Section 2 presents the setup of this system and our protocol for calibration of our measurements. Using two water vapor isotope analyzers calibrated independently of each other allows us to estimate the accuracy and precision of our observations. Section 3 is devoted to the investigation of statistical relationships and drivers for the observed variability in the d-excess: seasonality, wind direction, and wind speed as well as effect of averaging over different number of days. 


\section{Materials and method}

\subsection{Meteorological observations}

As shown in Fig. 1, our water vapor isotope monitoring system was installed at the Tudor Hill Atmospheric Observatory in Bermuda $\left(32.26^{\circ} \mathrm{N} 64.88^{\circ} \mathrm{W}\right)$. Air temperature and relative humidity $(\mathrm{RH})$ were recorded using a Campbell Scientific CR1000 logger $\left( \pm 0.1{ }^{\circ} \mathrm{C}\right.$ and $\left.\pm 2 \% \mathrm{RH}\right)$ and wind direction and speed using a RM Young propeller-type vane $\left( \pm 3^{\circ}\right.$ and $\pm 0.3 \mathrm{~m} \mathrm{~s}^{-1}$ ). Distribution of wind direction and speed is shown in Fig. 1d, indicating that the wind is predominantly straight in from the ocean $(\sim 65 \%$ occurrence). Surface pressure data values are obtained from the meteorological observations taken by the Bermuda Weather Service at Bermuda's L. F. Wade International Airport nearby. During the few days when we had meteorological data gaps at Tudor Hill, we used the airport observations by the Bermuda Weather Service. Monthly SST data were obtained by averaging daily MODIS (Moderate Resolution Imaging Spectroradiometer) Aqua satellite observations over a $\sim 600 \mathrm{~km} \times 800 \mathrm{~km}$ area centered on Bermuda (Haines et al., 2007; Acker and Leptoukh, 2007). Mean monthly air temperature data range from $17.7^{\circ} \mathrm{C}$ (February, mean daily high/low: $19.8 / 15.5^{\circ} \mathrm{C}$ ) to $27.2^{\circ} \mathrm{C}$ (August, mean daily high/low: $29.8 / 24.5^{\circ} \mathrm{C}$ ). Monthly mean SSTs vary from 18.4 to $28.2^{\circ} \mathrm{C}$ (minimum/maximum: March/August). Monthly climatology data from 1949 to 1999 (air temperature and SST) were obtained from the Bermuda Weather Service. Other measurements carried out at the tower consist of sampling for the Global Atmosphere Passive Sampler Network, continuous lower atmosphere ozone measurements and discrete greenhouse gas sampling for NOAA's Earth System Research Laboratory, continuous measurements of aerosol optical depth for NOAA's Aerosol Robotic Network, and continuous solar radiation measurements for NOAA's Baseline Surface Radiation Network.

\subsection{Setup}

We installed in November 2011 a water vapor isotope analyzer from Picarro Inc. (Model \# HBDS-2120) at the Tudor Hill Atmospheric Observatory in Bermuda, where the base of the meteorological tower is $\sim 29$ ma.s.l. (meters above sea level) and situated $\sim 30 \mathrm{~m}$ from the coast. The instrument is installed inside a temperature-regulated box ensuring daily temperature variability $<0.2^{\circ} \mathrm{C}$, which itself is placed inside an air-conditioned container where diurnal temperature variability is $<2{ }^{\circ} \mathrm{C}$. The setup of the system (Fig. 1c) is similar to the setup previously deployed above the Greenland ice sheet (Steen-Larsen et al., 2013, 2014). Three inlets were initially installed on the tower at a height of $\sim$ $20.5 \mathrm{~m}$ above ground ( $\sim 49 \mathrm{~m}$ a.s.l.), $\sim 13.1 \mathrm{~m}$ above ground ( $\sim 42 \mathrm{~m}$ a.s.l.), and $\sim 5.8 \mathrm{~m}$ above ground $(\sim 35 \mathrm{~m}$ a.s.l.). In June 2013 we installed a separate fourth inlet $\sim 2.5 \mathrm{~m}$ a.s.l.
The measurements that we focus on in this paper were taken from the top inlet place $\sim 49 \mathrm{~m}$ a.s.l., which is well above the local vegetation (scrub).

Air sampling is performed using copper tubing, as laboratory experiments showed copper to cause less smoothing of the signal compared to, for example, stainless steel and polytetrafluoroethylene (PTFE). All inlet tubes were placed inside Armaflex ${ }^{\circledR}$ closed-cell tube insulation and heated to above $50^{\circ} \mathrm{C}$ using self-regulating heat trace from Raychem ${ }^{\circledR}$. To prevent rain from being sucked into our air sampling tubes, the entrance of the inlets was placed inside Nalgene ${ }^{\circledR}$ bottles with their bottoms removed and substituted by a wire mesh screen to prevent intrusion of foreign objects, such as insects. An extra shield was placed above the inlets for protection against frequent intense precipitation events. A $10 \mathrm{~L} \mathrm{~min}^{-1}$ air pump ensures a quick transport of the air from the start of the inlet and into the analyzer. An extra $5 \mathrm{~L} \mathrm{~min}^{-1}$ air pump maintains a constant flow in the tubes not being sampled. Inside the temperature-regulated box, a manifold operated by the analyzer controls which inlet is being measured. A three-way valve controls whether the analyzer measures ambient water vapor, or water vapor from the calibration unit. The purpose of the calibration unit is to supply the analyzer with water vapor of known isotopic composition. This is achieved by using a similar vapor source to that described by Ellehoj et al. (2013). Dry air is let to slowly bubble through water of a known isotopic composition kept at a constant temperature inside a glass bottle $(5 \mathrm{~L})$. Ellehoj et al. (2013) showed that the water vapor isotopes are stable over flow rates up to $150 \mathrm{~mL} \mathrm{~min}^{-1}$, which is well above the flow rates used here $\left(\sim 30 \mathrm{~mL} \mathrm{~min}^{-1}\right)$. As the temperature of the system is very stable, the known isotopic composition and temperature of the water are used to calculate the isotopic composition of the generated water vapor under the assumption of isotopic equilibrium. This saturated water vapor is instantly diluted with dry air (humidity level below 200 ppmv generated from Drierite ${ }^{\circledR}$ ) as it leaves the glass bottle to prevent any condensation in the tubes and thus isotopic fractionation. We used this vapor generation system to perform humidity-isotope response calibrations and for drift corrections, as introduced in Steen-Larsen et al. (2013) and described hereafter.

\subsection{Calibration}

As described in Steen-Larsen et al. (2013) it is necessary to perform a humidity-isotope response calibration of the analyzer, and correct the raw measurements. Following the protocol described in Steen-Larsen et al. (2013), water vapor with a constant isotopic composition is introduced into the instrument at different humidity levels, obtained by diluting the saturated water vapor coming out of our bubbler system. We vary the humidity in steps of $10 \mathrm{~min}$, but start and finish the sequence at the same humidity level in order to correct for drift of the system. The drift is assumed to be linear 
A

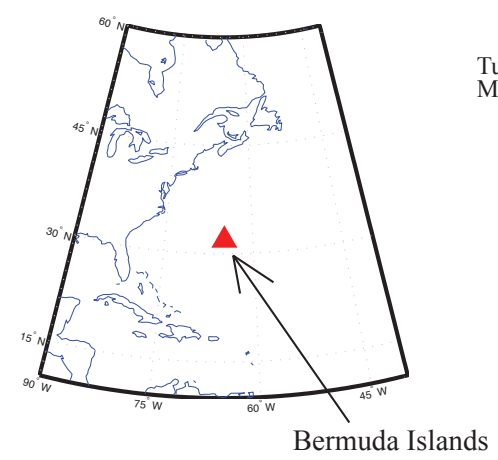

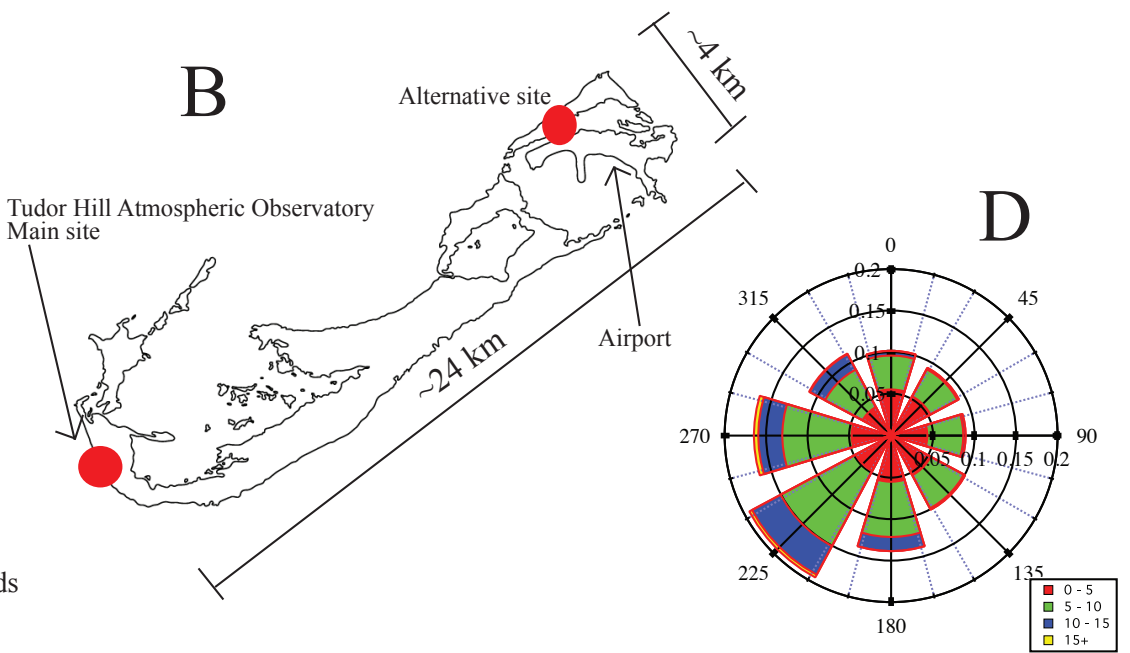
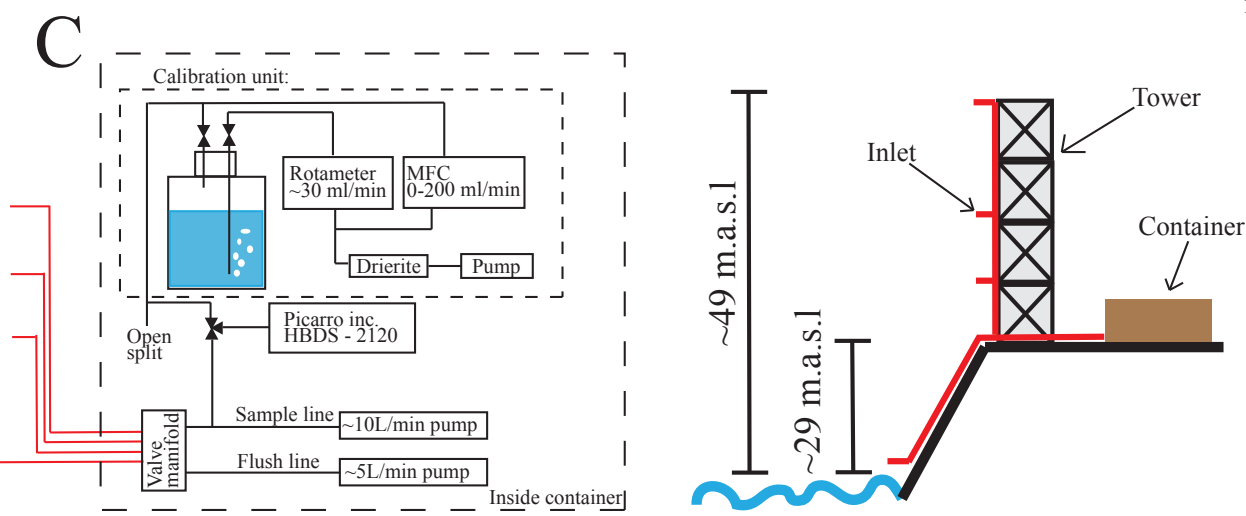

Figure 1. Illustration of the position of the Bermuda Islands (A), map of the sites where observations have been performed at Tudor Hill Atmospheric Observatory and on the other site of the island (B), and system setup (C). The wind rose (6-hourly observations) indicates that the wind is predominantly arriving at Tudor Hill directly from the ocean (D).

between the start and stop of each sequence. To assess the stability of the humidity-isotope response through time, calibrations were repeated at different dates (Fig. 2). Small but significant drifts in the humidity-isotope response curve are observed over the monitoring period. To correct for this observed drift of the humidity-isotope response, we assume the drift to be linear between two consecutive humidity-isotope response calibrations.

To reference our measurements against the International Atomic Energy Agency (IAEA) VSMOW-SLAP (Standard Light Antarctic Precipitation) scale, we measured standards of known isotopic composition. Between 3 and 10 different standards, which varied between $\sim 0$ and $\sim-39 \%$ in $\delta^{18} \mathrm{O}$ and between $\sim 0$ and $-310 \%$ in $\delta D$, were used each time we carried out a VSMOW-SLAP calibration. The standards used were referenced by the Institute of Arctic and Alpine Research at the University of Colorado, the Centre for Ice and Climate at the University of Copenhagen, and Laboratoire des Sciences du Climat et de l'Environnement in Gif-sur-Yvette, and calibrated against the IAEA VSMOWSLAP scale. The standard deviation of the residuals between the VSMOW-SLAP value of the standards and the calcu- lated values based on best linear fits is $\sim 0.1 \%$ o for $\delta^{18} \mathrm{O}$ and $\sim 1.1 \%$ ofor $\delta D$. We carried out VSMOW-SLAP calibrations in November 2011, August/September 2012 (most intensive period of calibrations, with 6 calibrations within 3 weeks), and June 2013 (Table 1). Table 1 rules out short-term variability for the VSMOW-SLAP slope but shows longterm changes in the slope, similar to values reported by Bastrikov et al. (2014). We assume that the VSMOW-SLAP slope varies linearly between the calibration periods. This observed drift is small, and has no impact on our data quality. The range of observed atmospheric water vapor isotope variability is less than $\sim 10 \%$ in $\delta^{18} \mathrm{O}$, and much smaller than the range of the standards. An unaccounted drift of 0.01 in the VSMOW-SLAP $\delta^{18} \mathrm{O}$ slope would, for example, result in a maximum bias of only $0.1 \%$ in $\delta^{18} \mathrm{O}$ of the measured atmospheric water vapor isotope signal.

To account for the drift of the measured atmospheric water vapor isotope signal, we measure every $6-12 \mathrm{~h}$ water vapor with a known isotopic composition. This is carried out using our bubbler system described above. We have monitored the isotopic composition of the water inside our bubbler by taking samples regularly for measurements on an isotope-ratio 
Table 1. Slope between IAEA VSMOW-SLAP values and measured values of standards.

\begin{tabular}{lcccccccc}
\hline Date & \multicolumn{2}{c}{ Slope } & \multicolumn{2}{c}{$\begin{array}{c}\text { Standard } \\
\text { deviation slope }\end{array}$} & Mean slope & \multicolumn{2}{c}{$\begin{array}{c}\text { Standard } \\
\text { deviation mean } \\
\text { slope }\end{array}$} \\
& $\delta^{18} \mathrm{O}$ & $\delta D$ & $\delta^{18} \mathrm{O}$ & $\delta D$ & $\delta^{18} \mathrm{O}$ & $\delta D$ & $\delta^{18} \mathrm{O}$ & $\delta D$ \\
\hline 27 Nov 2011 & 1.0708 & 1.0685 & 0.0206 & 0.0104 & - & - & - & - \\
\hline 28 Aug 2012 & 1.0713 & 1.0915 & 0.0029 & 0.0055 & 1.0733 & 1.09315 & 0.0052 & 0.0078 \\
31 Aug 2012 & 1.0756 & 1.0886 & 0.0062 & 0.0047 & & & & \\
4 Sep 2012 & 1.0690 & 1.0949 & 0.0033 & 0.0033 & & & & \\
6 Sep 2012 & 1.0812 & 1.1081 & 0.0203 & 0.0051 & & & & \\
10 Sep 2012 & 1.0756 & 1.0883 & 0.0023 & 0.0100 & & & & \\
15 Sep 2012 & 1.0669 & 1.0875 & 0.0026 & 0.0064 & & & & \\
\hline 13 Jun 2013 & 1.0527 & 1.0759 & 0.0044 & 0.0049 & 1.0547 & 1.0756 & 0.0022 & 0.0003 \\
2 Jul 2013 & 1.0571 & 1.0753 & 0.0014 & 0.0024 & & & & \\
3 Jul 2013 & 1.0543 & 1.0755 & - & - & & & & \\
\hline
\end{tabular}
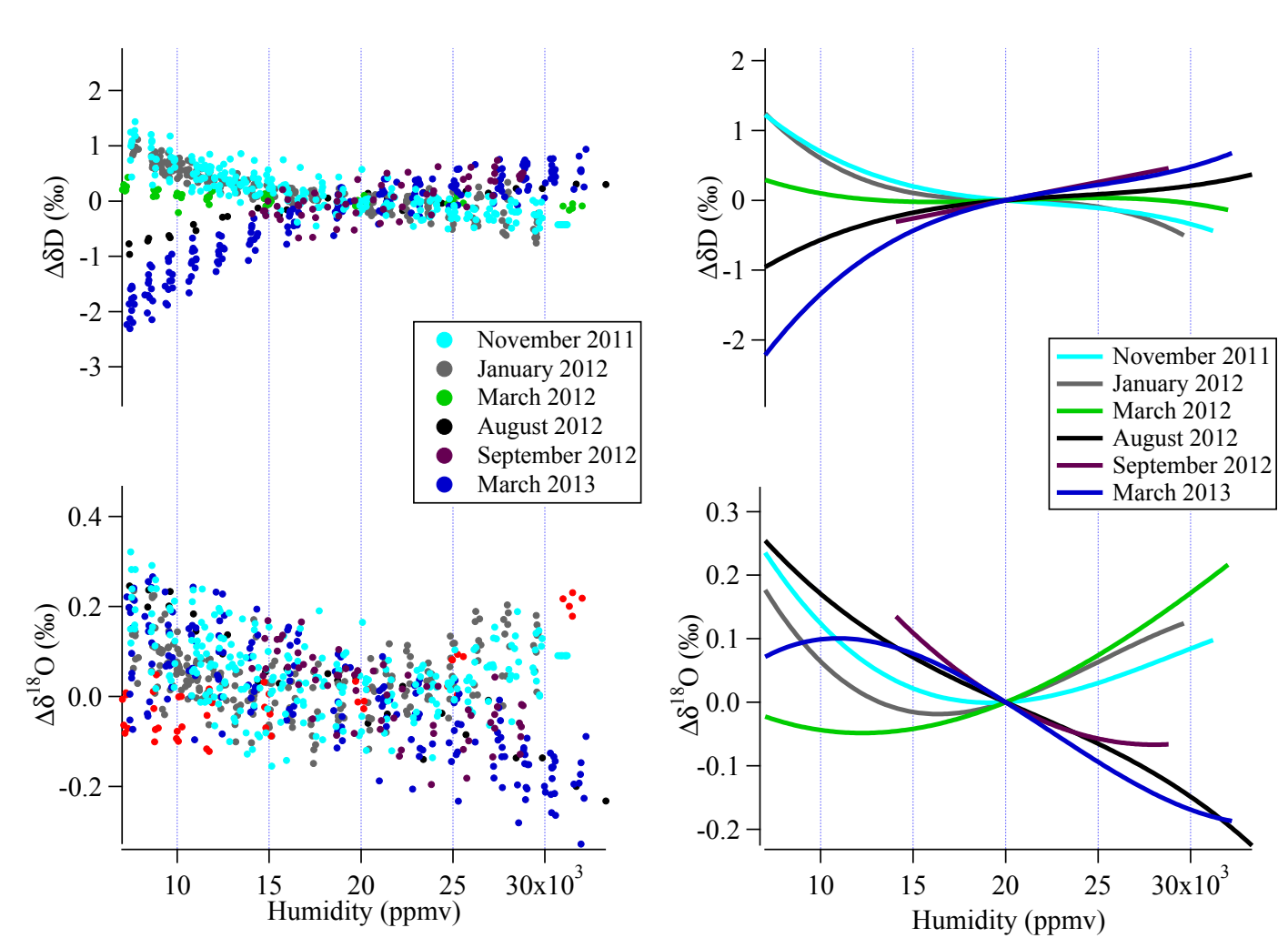

Figure 2. Humidity-isotope response calibrations of the analyzer performed at different dates during the monitoring period. The right panel represents the best fit using either a second- or third-order polynomial to the observations.

mass spectrometry (IRMS) system. As expected from the minor removal of water vapor $(\sim 0.03 \mathrm{~g} / \mathrm{drift}$ calibration) and large water body $(5 \mathrm{~L})$, no change in the liquid water isotopic composition was detected. The water vapor from the bubbler is measured for $30 \mathrm{~min}$, of which the first $15 \mathrm{~min}$ are discarded due to memory effects. The raw measurements are corrected using our humidity-isotope response correction (Fig. 2). They are then calibrated against VSMOW-SLAP using the slopes presented in Table 1 and drift-corrected using the measurements of the vapor from the bubbler and the expected isotopic composition of the water vapor calculated from the equilibrium fractionation coefficient and the liquid water isotope value.

Figure 3 shows the long-term drift of the system, characterized for $\delta^{18} \mathrm{O}$ and $\delta D$ by a $\sim 3 \%$ increase and a $\sim 7 \%$ odecrease over the $\sim 1.5 \mathrm{yr}$ measurement period. The associated 


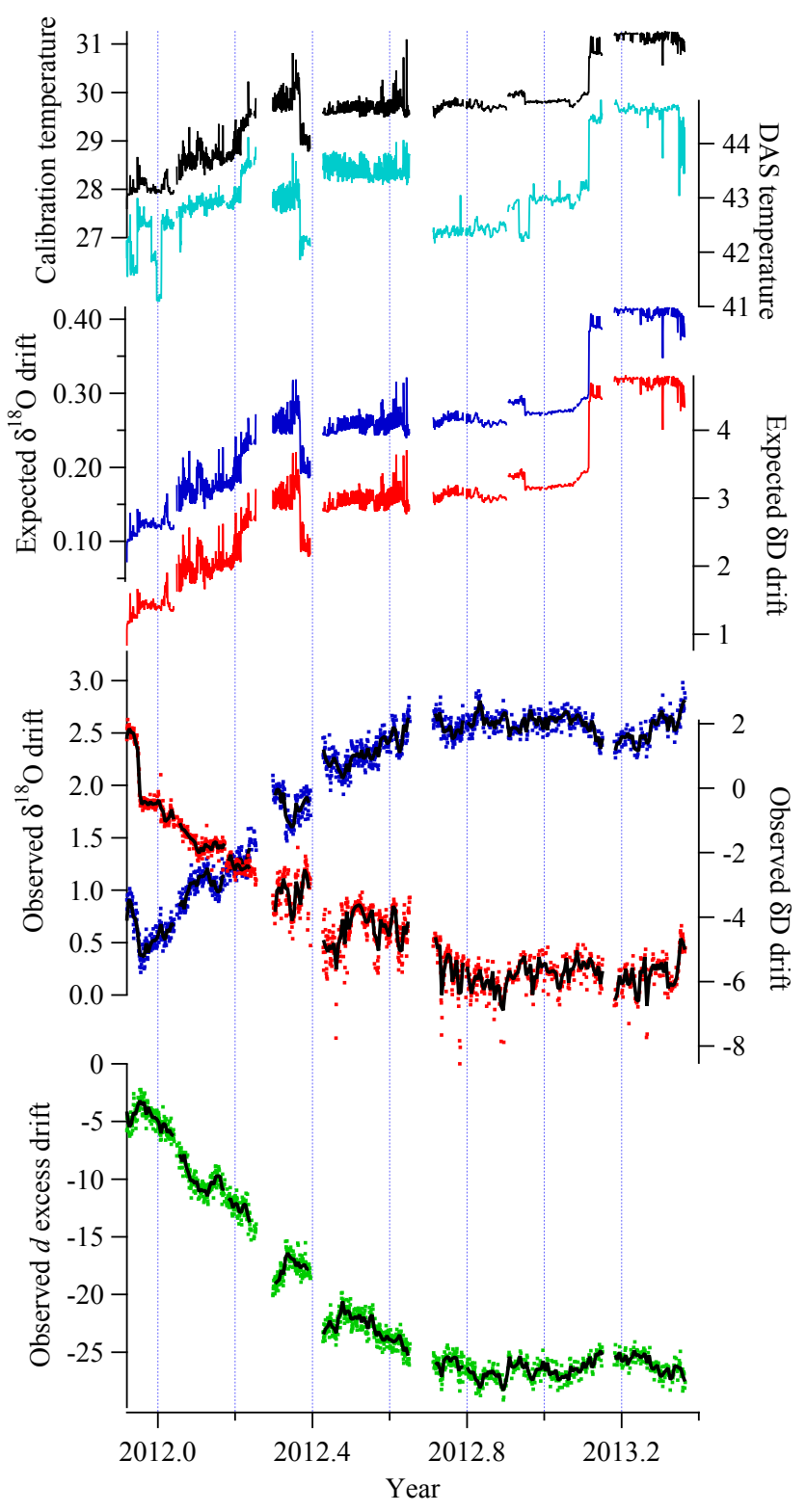

Figure 3. Drift on the measured isotopic values. The top panel shows the temperature of the water body in the bubbler system. Below is shown the internal temperature of the Picarro analyzer (DAS temperature). The theoretical drift of the calibration water vapor isotopes is calculated based on the drift of the calibration temperature. The observed drift in $\delta^{18} \mathrm{O}, \delta D$, and d-excess is shown for individual measurements in blue, red, and green dots, respectively. The $48 \mathrm{~h}$ running mean is shown using a black solid line.

$\sim 25 \%$ o drift of d-excess stresses the uttermost importance of this correction. No apparent reason for this drift could be determined. The stable isotopic measurements of water samples taken from the bubbler rule out a drift of the standard itself. We note a long-term correlation between the drift and the temperature of the calibration system and analyzer (Fig. 3). However, abrupt changes in the temperature do not

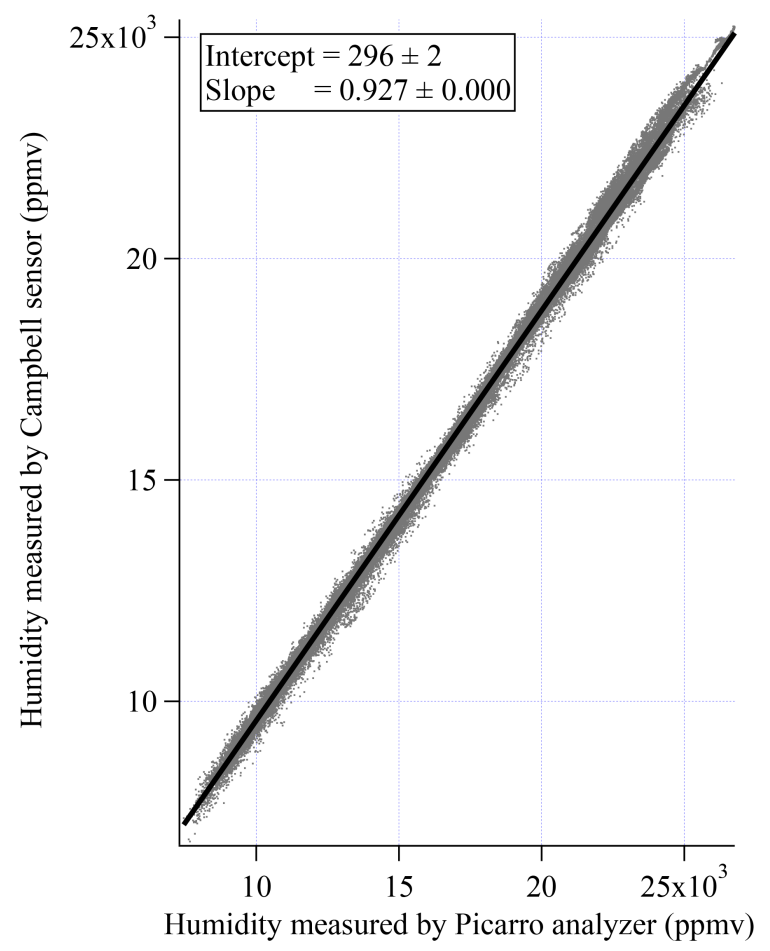

Figure 4. Relationship between the observed absolute humidity by the Campbell humidity sensor ( $y$ axis) and the measurement by the Picarro analyzer ( $x$ axis). This relationship is used to correct the Picarro humidity measurements.

seem to induce any response of the system. A $48 \mathrm{~h}$ running mean (black line, Fig. 3) is used to drift-correct the measurements of the atmospheric water vapor isotopes.

The Picarro humidity measurements are calibrated against the estimated absolute humidity (ppmv) from the Campbell humidity sensor showing a strong linear relationship (Fig. 4). Humidity $(\mathrm{ppmv})=p_{\mathrm{w}} /\left(p_{\text {tot }}-p_{\mathrm{w}}\right) 10^{6}$, where $p_{\mathrm{w}}$ and $p_{\text {tot }}$ is the vapor pressure and the total pressure. Hereafter, we use the corrected Picarro humidity values.

\subsection{Signal smoothing due to the experimental setup}

Due to the length of the introduction line ( $25 \mathrm{~m}$ of tubing), we expect the signal to be smoothed through mixing and interactions with the inside tube wall (Massman and Ibrom, 2008). By using a $10 \mathrm{~L} \mathrm{~min}^{-1}$ pump to transport the sample quickly from the inlet to the analyzer we try to minimize the smoothing of the signal from the interactions between the water vapor and the walls of the tubing. In order to quantify this effect, two sets of experiments were performed. We first injected air with two significantly different water vapor concentrations ( $\sim 1000$ and $\sim 30000 \mathrm{ppmv})$ and secondly injected air containing the same concentration of water vapor, but with two significantly different water vapor isotopic compositions $\left(\delta^{18} \mathrm{O}: \sim-56 \%\right.$ and $\sim-17 \%$ o). We used a similar system as our calibration system described 

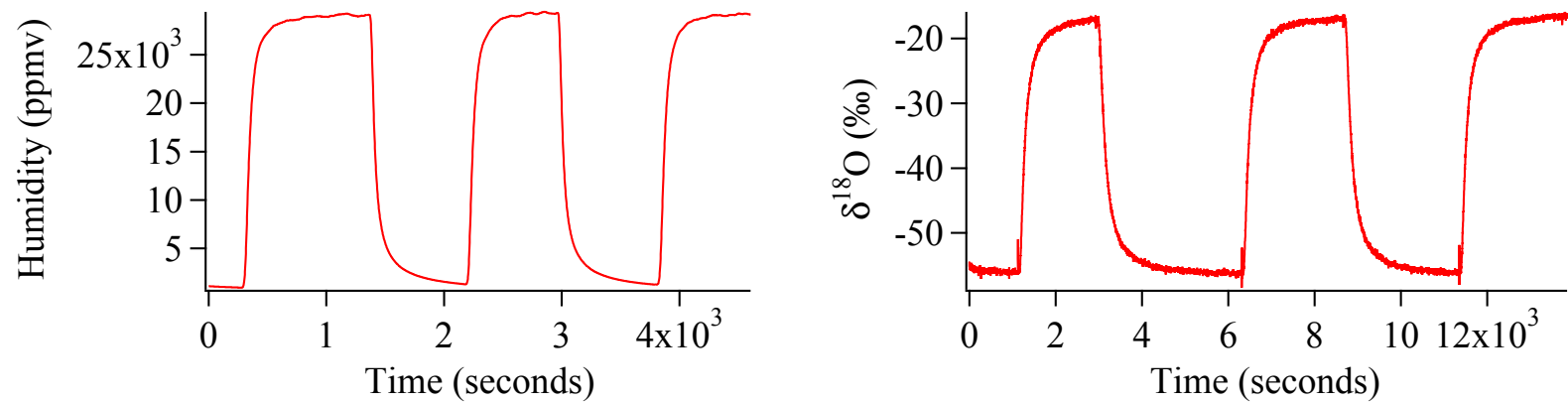

Figure 5. Results of experiments conducted to characterize the response time of the system. Step changes of humidity followed by step changes in $\delta^{18} \mathrm{O}$ were performed. Note that the steps are not of equal length as the experiment was performed on an ad hoc field setup on top of the tower.

in Sect. 2.2 to generate the water vapor with the given isotope and humidity value. The observed step changes in the humidity and isotope values are shown in Fig. 5. The normalized response functions for the shifts in humidity, $\delta^{18} \mathrm{O}$, and $\delta D$ together with the averaged time derivative of the normalized response functions are shown in Fig. 6. A lognormal distribution gives a good fit (not shown) to the time-derived normalized response functions. The lag-time for the signal to arrive at the analyzer (defined as the time at which $0.5 \%$ of the normalized response has been reached) is shorter for the humidity $(\sim 40 \mathrm{~s})$ than for the isotopes $(\sim 50 \mathrm{~s})$. Similarly, $95 \%$ of the normalized response is obtained after respectively $\sim 225, \sim 650$, and $\sim 1200$ s for the humidity, $\delta^{18} \mathrm{O}$, and $\delta D$ signal. This smoothing of the signal between the inlet and the analyzer causes different memory effects on each parameter. Since the performed step changes can be approximated by a Heaviside step function for the humidity and isotopic change, the first time-derivative of the original humidity and isotope signal becomes a Dirac delta function. The transfer function (i.e., the dampening of the signal at different frequencies) of the complete setup can therefore be estimated from the Fourier transform of the time derivative of the normalized change. This is shown in Fig. 7 for humidity (black lines), $\delta^{18} \mathrm{O}$ (blue lines), and $\delta D$ (red lines). A signal with a periodicity of $\sim 100 \mathrm{~s}$ will be attenuated by $\sim 85 \%$ in humidity, $98.5 \%$ in $\delta^{18} \mathrm{O}$, and $99.7 \%$ in $\delta D$. However, it is potentially possible to record humidity signals with a periodicity down to $\sim 30 \mathrm{~s}$. Due to a compensation between larger smoothing and lower noise level for $\delta D$ (compared to $\delta^{18} \mathrm{O}$ ), it is possible to observe signals in both $\delta D$ and $\delta^{18} \mathrm{O}$ with a periodicity down to $\sim 60 \mathrm{~s}$. Using the estimated transfer function for $\delta D$ and $\delta^{18} \mathrm{O}$ and the fact that the measured signal is equal to the original signal convoluted by a lognormal function, it could be possible to perform a back-smoothing correction and recreate the original high-frequency signal using similar techniques to those applied to ice core waterstable isotope records or eddy-covariance analysis (Johnsen, 1977; Johnsen et al., 2000; Spank and Bernhofer, 2008).

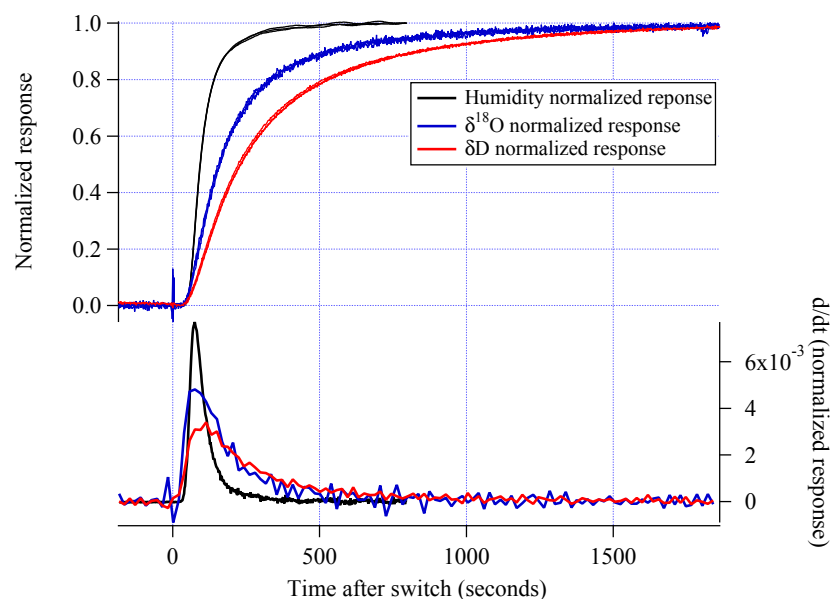

Figure 6. Normalized response function for humidity, $\delta^{18} \mathrm{O}$, and $\delta D$ (upper panel). Time derivative of the normalized response functions (lower panel).

\subsection{Instrumental inter-comparison and inter-site variability}

During autumn 2012, a second Picarro Inc. analyzer was installed in parallel with the original analyzer for a short period of time. Each analyzer was calibrated independently using the above procedure. The comparison of the two records allows us to directly estimate the uncertainty of the measured water vapor isotope signal, including the uncertainty of the calibration steps. Based on $10 \mathrm{~min}$ averaged calibrated data from the two analyzers, spanning a period of 5 days (Fig. 8), the inter-instrument differences are normally distributed with a mean and standard deviation of $0.05 \pm 0.14 \%$ o $\left(\delta^{18} \mathrm{O}\right),-0.15 \pm 0.85 \% \circ(\delta D)$, and $0.3 \pm 1.1 \%$ (d-excess). The mean deviation for $\delta^{18} \mathrm{O}, \delta D$, and d-excess being close to zero rules out any systematic bias between the two analyzers. Following Steen-Larsen et al. (2013), the standard deviation of the inter-instrument differences is used as a conservative estimate for our precision. Our obtained precision of $1.1 \%$ or for d-excess far exceeds the precision of water 


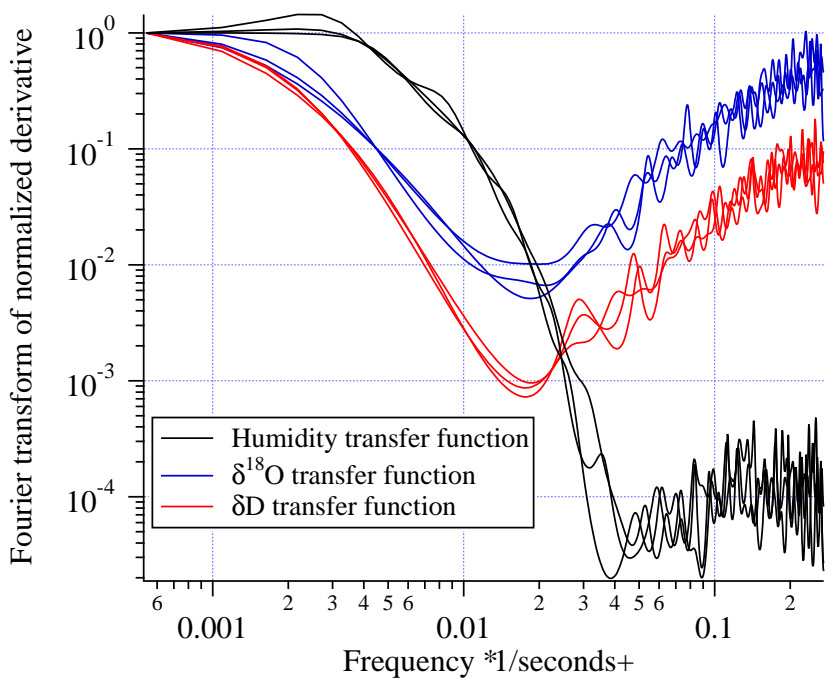

Figure 7. Fourier transform of the time derivative normalized response functions for humidity, $\delta^{18} \mathrm{O}$, and $\delta D$. The transfer functions of the humidity and isotopes are estimated for each of the 3 steps shown in Fig. 5.

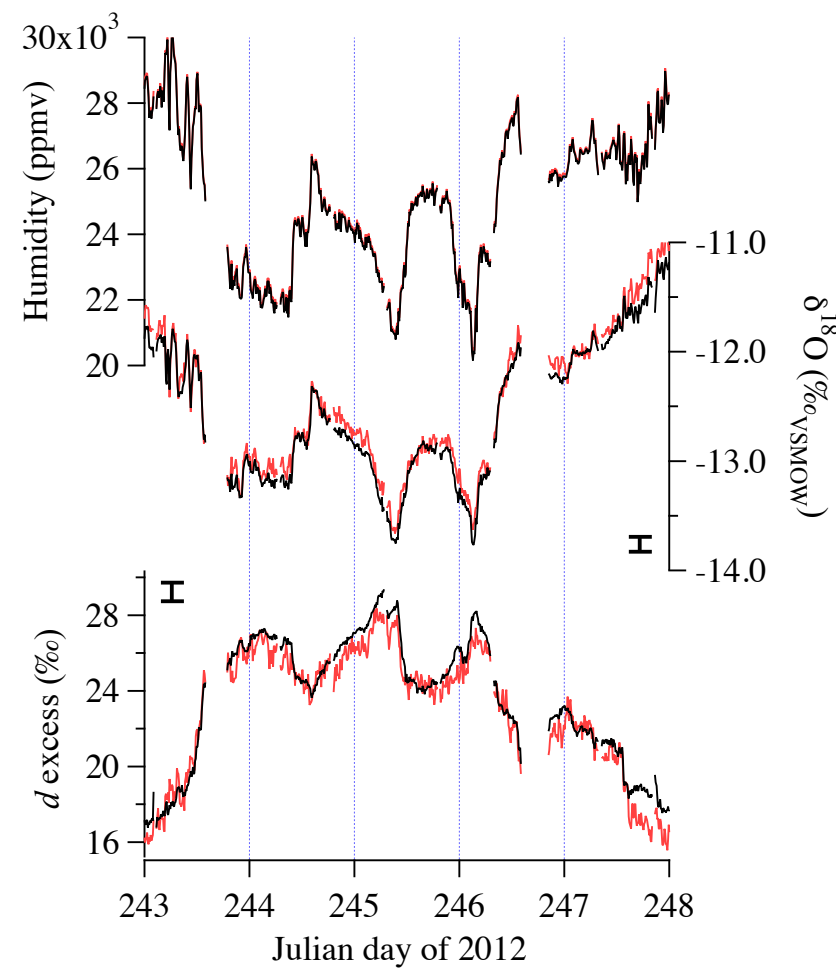

Figure 8. Observed humidity, $\delta^{18} \mathrm{O}$, and d-excess by two independently calibrated water vapor isotope analyzers installed in parallel using the same inlet on the tower. The observations are reported as $10 \mathrm{~min}$ averages. The estimated uncertainties for $\delta^{18} \mathrm{O}$ and d-excess based on the standard deviation of the inter-instrument anomaly $(0.14 \%$ and $1.1 \%$ ) are indicated next to the axes.
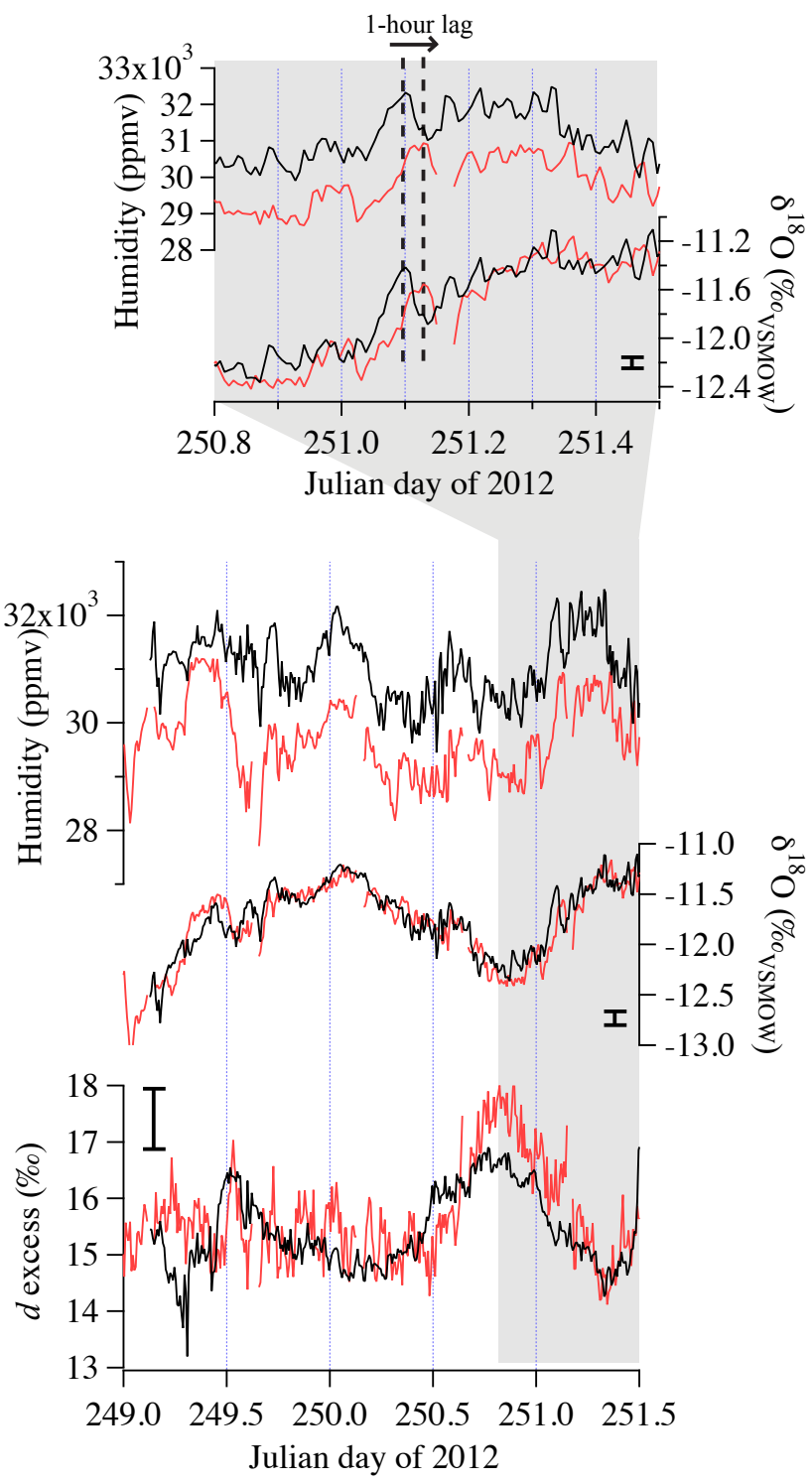

Figure 9. Humidity, $\delta^{18} \mathrm{O}$, and d-excess measured by two water vapor analyzers separated to opposite ends of the island. We highlight an event where an increase in humidity and $\delta^{18} \mathrm{O}$ is first recorded at the northern site and $1 \mathrm{~h}$ later at Tudor hill as expected by surface wind direction and wind speed during this period. The estimated uncertainties for $\delta^{18} \mathrm{O}$ and d-excess $(0.14$ and $1.1 \%$ ) are indicated next to the axes.

vapor cryogenic trapping capabilities and reaches the precision achieved by IRMS.

In order to investigate the regional coherency of the observed water vapor isotopes, we moved the second analyzer to the opposite end of the Bermuda Islands, located $20 \mathrm{~km}$ away from the Tudor Hill Atmospheric Observatory (Fig. 1), for a period of $\sim 3$ days at the beginning of autumn (Julian day 249-252 of 2012). The comparison of the two records (Fig. 9) depicts a gradient in humidity levels, probably due to the altitude at which measurements were 


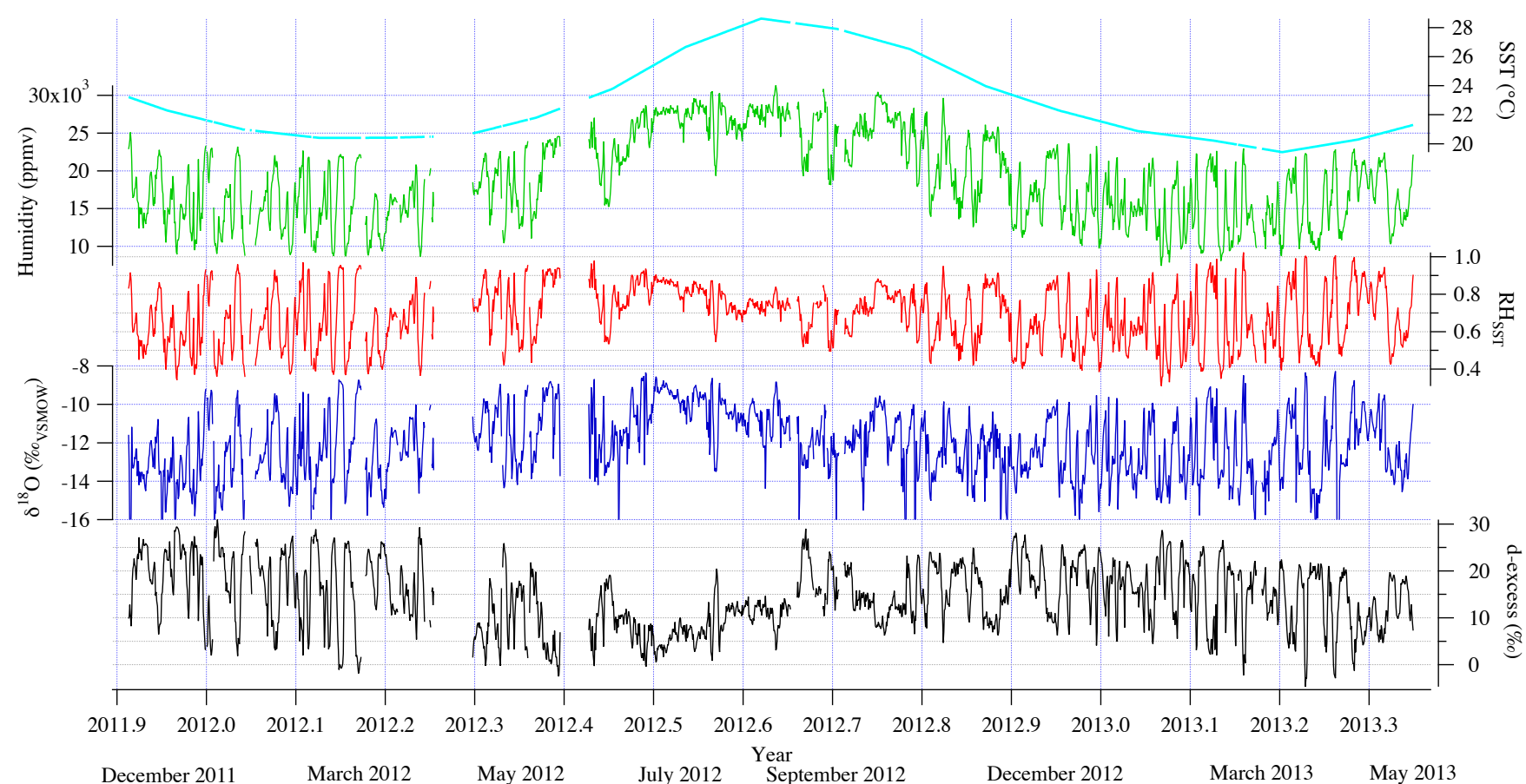

Figure 10. SST, humidity, and water vapor isotopic composition monitored between November 2011 and June 2013. From top to bottom are shown the sea surface temperature $\left({ }^{\circ} \mathrm{C}\right.$, cyan), humidity (ppmv, green), the relative humidity at sea surface temperature (red), the water vapor $\delta^{18} \mathrm{O}(\%$, blue), and d-excess (\%o, black).

conducted $(\sim 15 \mathrm{~m}$ a.s.l vs. $\sim 49 \mathrm{~m}$ a.s.l. for Tudor Hill). Altogether, a very good agreement is observed between observations at either end of the island. During an event at which the wind blew parallel with the axis formed by the two stations, at day 251.1, we observe a $1 \mathrm{~h}$ delay between the first increase of humidity and water vapor isotopic composition at the northern site (Fig. 9, black solid line), and the same signals recorded at Tudor Hill ( $20 \mathrm{~km}$ away). This is fully consistent with air mass transportation at the mean wind speed of about $20 \mathrm{~km} \mathrm{~h}^{-1}$ without any significant change in the magnitude of the water vapor isotopic signal between the two sites. Based on this short comparison, we conclude that the signal measured at Tudor Hill is representative of a regional signal, without any significant local effects.

\section{Results and discussions}

During the more than 500-day measurement period the SST is found to vary between $\sim 20$ and $\sim 28^{\circ} \mathrm{C}$ with minimum and maximum occurring around mid-March and mid-July (Fig. 10, light blue curve). Figure 10 shows our corrected records of humidity (green), relative humidity at to SST (red), $\delta^{18} \mathrm{O}$ (blue), and d-excess (black) for the period between November 2011 and June 2013 (6 h data). Thanks to limited prolonged data gaps our data coverage is $95 \%$. The first gap in the data $(\sim 2012.25)$ was due to a flooded inlet caused by heavy rain, while the second gap ( 2012.4) was due to a failure of a vacuum pump.

The full year of data from 2012 allow us to compute the annual mean value for the humidity, $\delta^{18} \mathrm{O}, \delta D$, and d-excess: $\sim 20500 \mathrm{ppmv}, 70 \%$ (RH $\left.\mathrm{RHST}_{\mathrm{ST}}\right),-11.81 \%$ o, $-80.8 \%$, and $13.7 \%$, respectively. We find for 2012 a well-defined maximum (minimum) for ${ }^{18} \mathrm{O}$ (d-excess) to occur in July $(-10.0$ and $7.3 \%$ ), while the months November-February have roughly similar minimum (maximum) $\delta^{18} \mathrm{O}$ (d-excess) mean values $(-12.5$ to $-12.8 \%$ and 16.8 to $17.7 \%$ ). Figure 10 clearly shows July-August to have less variability (standard deviation $(\sigma)$ of the $6 \mathrm{~h}$ data) in $\delta^{18} \mathrm{O}$ and d-excess: $\sim 1.03$ and $\sim 3 \%$ o less than January-February $\left(\sigma\left(\delta^{18} \mathrm{O}\right)\right.$ and $\sigma(\mathrm{d}-$ excess): $\sim 1.8$ and $\sim 9 \%$ ). We notice the absence of a significant diurnal variation in the humidity and isotopes, indicating the absence of local diurnal processes related to the boundary layer and plant transpiration (Welp et al., 2012; Berkelhammer et al., 2013).

From the 6-hourly data, d-excess is strongly correlated with $\mathrm{RH}_{\mathrm{SST}}(n=\sim 2100, R=-0.93)$, with a slope of $-42.6 \pm 0.4 \%$ / \% (Table 2, Fig. 11a). For the remainder of this section, we further investigate the stability of the relationship between d-excess and $\mathrm{RH}_{\mathrm{SST}}$, comparing the results obtained under different wind regimes and different seasons (based on SST values).

The observed relationships are compared to theoretical calculations based on MJ79 performed for a smooth surface 
Table 2. The slope and intersect of d-excess vs. relative humidity for the complete data set as well as seasonal, wind direction, and wind speed subsets.

\begin{tabular}{llcccc}
\hline \multirow{2}{*}{ All data } & & $\begin{array}{c}\text { Slope } \\
\left(\% \circ\left(\mathrm{RH}_{\mathrm{SST}}{ }^{-1}\right)\right)\end{array}$ & $\begin{array}{c}\text { Intercept } \\
(\% \circ)\end{array}$ & $R^{2}$ & $N$ \\
& & $-42.6 \pm 0.4$ & $43.5 \pm 0.3$ & 0.86 & 1926 \\
& High wind speed $\left(>7 \mathrm{~m} \mathrm{~s}^{-1}\right)$ & $-42.0 \pm 0.5$ & $42.9 \pm 0.4$ & 0.89 & 679 \\
& Low wind speed $\left(<6 \mathrm{~m} \mathrm{~s}^{-1}\right)$ & $-43.0 \pm 0.6$ & $43.9 \pm 0.4$ & 0.82 & 1016 \\
\hline \multirow{2}{*}{ Summer data } & & $-51.9 \pm 1.5$ & $50.8 \pm 1.1$ & 0.76 & 398 \\
& Wind direction $0-180^{\circ}$ & $-45.2 \pm 2.1$ & $46.3 \pm 1.5$ & 0.69 & 208 \\
& Wind direction $180-360^{\circ}$ & $-56.7 \pm 2.1$ & $54.1 \pm 1.6$ & 0.80 & 180 \\
\hline \multirow{2}{*}{ Winter data } & & $-40.7 \pm 0.5$ & $41.4 \pm 0.4$ & 0.88 & 738 \\
& & $-41.7 \pm 0.8$ & $42.5 \pm 0.6$ & 0.88 & 287 \\
& Wind direction $0-200^{\circ}$ & $-49.1 \pm 1.0$ & $48.6 \pm 0.8$ & 0.92 & 164 \\
& Wind direction 200-250 & $-38.7 \pm 1.1$ & $39.8 \pm 0.6$ & 0.82 & 275 \\
\hline \multirow{2}{*}{ Autumn data } & Wind direction 250-360 & $-37.4 \pm 1.1$ & $41.8 \pm 0.7$ & 0.90 & 135 \\
\hline Spring data & & $-39.1 \pm 1.8$ & $40.0 \pm 1.4$ & 0.85 & 90 \\
\hline
\end{tabular}

(wind speed below $6 \mathrm{~m} \mathrm{~s}^{-1}$ ) and a rough surface (wind speed above $7 \mathrm{~m} \mathrm{~s}^{-1}$ - kinetic fractionation value taken for $10 \mathrm{~m} \mathrm{~s}^{-1}$ ) and for SST of $20^{\circ} \mathrm{C}$ and $30^{\circ} \mathrm{C}$. The best linear fit to our observations is extremely close to MJ79 predictions for a smooth surface, and bracketed by calculations for SST between 20 and $30^{\circ} \mathrm{C}$. It is also found that the predictions corresponding to a rough surface and SST of $20^{\circ} \mathrm{C}$ constitute a lower bound for the observations.

Note that this comparison relies on the implicit assumption that Tudor Hill winds and relative humidity (measured at about 49 m a.s.l.) are representative of meteorological conditions of the lower boundary layer. Based on the similarity of humidity variations (despite a systematic offset) with the other end of the Bermuda Islands (Fig. 1), and the lack of a strong diurnal variability, which could be driven by changes in the marine boundary layer height, we assume this implicit hypothesis to be valid.

In order to investigate if the observed relationship depends on the wind regime, Fig. 11b shows the subsets of observations corresponding to wind conditions associated with a smooth surface (wind speed $<6 \mathrm{~m} \mathrm{~s}^{-1}$ - blue dots) and a rough surface (wind speed $>7 \mathrm{~m} \mathrm{~s}^{-1}-$ red dots). We made the separation according to the discontinuity in the kinetic fractionation factor defined by MJ79. A small difference between the two subsets appears for $\mathrm{RH}_{\mathrm{SST}}<0.6$, with smooth conditions associated with higher ranges of d-excess. The slope of the relationship between d-excess and $\mathrm{RH}_{\mathrm{SST}}$ is slightly more negative $(-43 \% / \%$ vs. $-42 \% / \%)$ for data corresponding to low winds (see also the Supplement). However, this observed difference is much smaller than inferred from MJ79 (from -42.7 to $-28.5 \%$ o $/ \%$ when shifting from smooth to rough surface). This indicates that either the wind regimes defined in MJ79 might not be appropriate for this area or the observed d-excess of the local water vapor is af- fected by past wind conditions at remote areas of evaporation. The differences between the result of this study and the results by Uemura et al. (2012) and Benetti et al. (2014) illustrates that more studies are needed to clarify the effect of wind speed on the d-excess signal in the marine boundary layer.

\subsection{Seasonal d-excess vs. RH}

We now investigate whether the relationship between $d$ excess and $\mathrm{RH}_{\text {SST }}$ varies as a function of SST and season. The winter period is defined for SST below $21.0^{\circ} \mathrm{C}$, summer for SST above $26.0^{\circ} \mathrm{C}$, and spring and autumn for SST between 23.0 and $25.0^{\circ} \mathrm{C}$. Figure $11 \mathrm{c}$ and $\mathrm{d}$ show the d-excess vs. $\mathrm{RH}_{\mathrm{SST}}$ for the different periods as well as the best linear fits (summarized in Table 2). The average $\mathrm{RH}_{\mathrm{SST}}$ for both the complete data set and for the winter subset data is approximately $60-65 \%$. Comparing for this $\mathrm{RH}_{\text {SST }}$ the absolute values of the best fit shown in Fig. 11 and in Table 2 reveals the winter d-excess to be about $1 \%$ lower compared to that for the complete data set $(\sim 17 \%$ o compared to $\sim 18 \%$ o). This offset is consistent with the theory of MJ79 and the dependency of d-excess on SST: $3^{\circ} \mathrm{C}$ lower winter SST is expected to decrease winter d-excess by approximately $1 \%$. With similar SST and RH ranges, we also observe that d-excess is systematically higher in autumn than in spring, which also translates into different intercepts of d-excess vs. $\mathrm{RH}_{\mathrm{SST}}$ regressions (Fig. 11d, Table 2). This feature, which cannot be explained by local meteorological parameters (i.e., SST), points to a change of moisture source region(s) and/or condition between spring and autumn. The validation of this hypothesis requires specific investigations such as moisture backtrajectory calculations and water tagging using atmospheric 

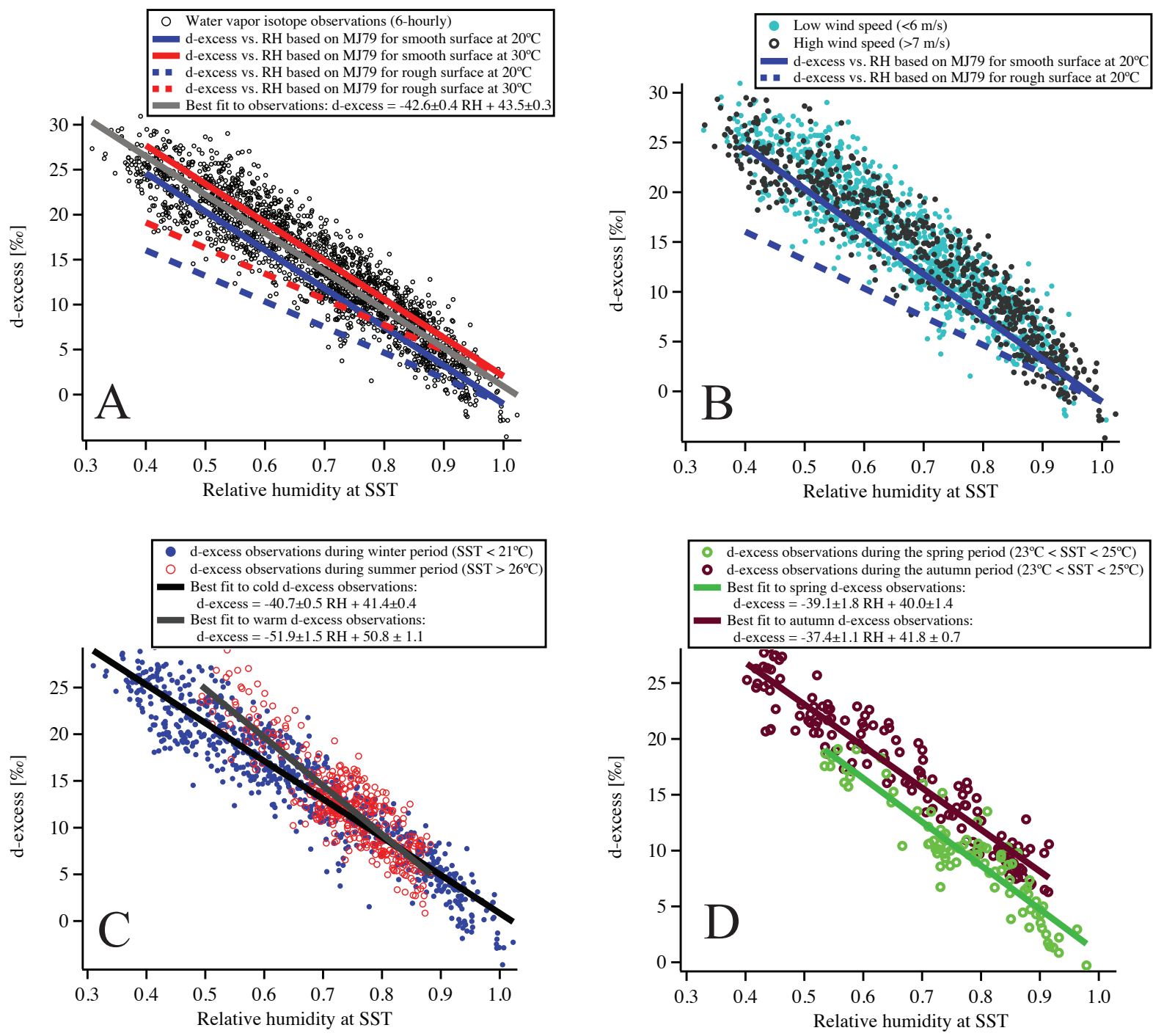

Figure 11. (A) Complete set of 6-hourly observations of d-excess vs. relative humidity ( $\mathrm{RH}_{\mathrm{SST}}$ ) at sea surface temperature (black dots), with a best fit (grey line). Results from the theory of MJ79 are displayed for a rough and smooth surface, and for SST of 20 and $30{ }^{\circ} \mathrm{C}$. (B) The complete set of 6-hourly observations of d-excess vs. $\mathrm{RH}_{\mathrm{SST}}$ separated into calm $\left(<6 \mathrm{~m} \mathrm{~s}^{-1}-\right.$ cyan dots) and strong winds $\left(>7 \mathrm{~m} \mathrm{~s}{ }^{-1}\right.$ - grey dots). MJ79 calculations are shown for a rough and smooth surface at $20^{\circ} \mathrm{C}$. (C) Observations collected during winter (defined as SST $<21^{\circ} \mathrm{C}$ - blue dots) and summer (defined as SST $>26^{\circ} \mathrm{C}-$ red dots) period. The best linear fits to winter and summer observations are shown as black and grey solid lines. (D) Observations collected during the spring $\left(23^{\circ} \mathrm{C}<\mathrm{SST}<25^{\circ} \mathrm{C}-\right.$ green dots $)$ and autumn $\left(23^{\circ} \mathrm{C}<\mathrm{SST}<25^{\circ} \mathrm{C}-\right.$ brown dots) period. Best linear fits to the spring and autumn period are shown as, respectively, green and brown solid lines.

general circulation models, which are beyond the scope of this manuscript.

Finally, Fig. 11c and d and Table 2 highlight that the slope between d-excess and $\mathrm{RH}_{\mathrm{SST}}$ is much more negative in summer than for other seasons. The distribution of the summer d-excess data shows a subset of points for $\mathrm{RH}_{\mathrm{SST}}>0.65$ which are aligned on the same d-excess vs. $\mathrm{RH}_{\mathrm{SST}}$ relationship as for the winter season. However, a subset of abnormal high summer d-excess data corresponding to $\mathrm{RH}_{\mathrm{SST}}<0.65$, and dominant northwesterly winds, lead to a much more negative slope with respect to local $\mathrm{RH}_{\mathrm{SST}}$. Section 3.3 will sys- tematically investigate the influence of wind direction on the d-excess.

\section{2 d-excess vs. RH on different timescales}

Figure 10 clearly depicts enhanced winter variability in surface humidity and isotopic composition. This is supported by a wavelet analysis (not shown here) showing significant power in the variability of the humidity and isotopes with periodicities between 3 and 8 days from mid-November to mid-February. During the summer months (mid-April to 


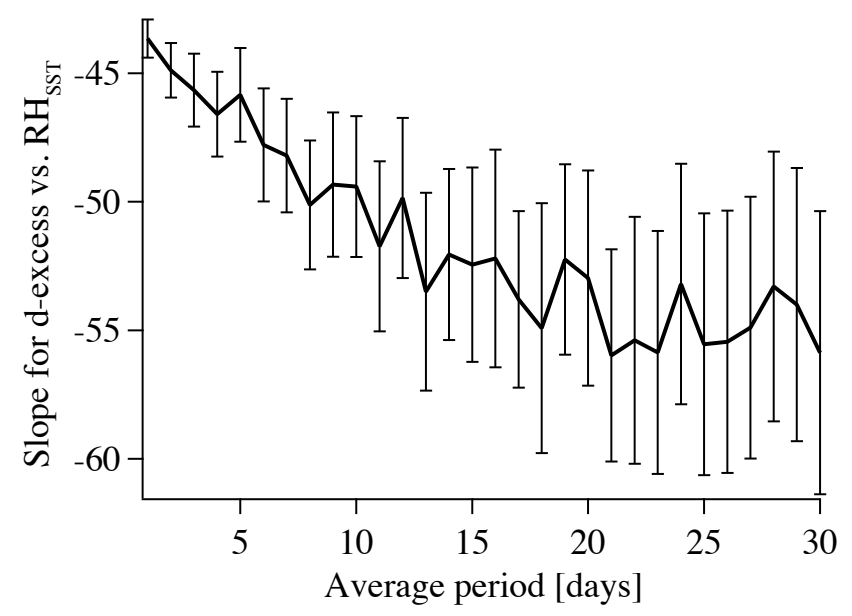

Figure 12. Slope of d-excess vs. $\mathrm{RH}_{\mathrm{SST}}$ for different averaging periods varying from 1 day to 30 days.

mid-September), no period with a significant power shows up. This is consistent with the buildup and westerly shift of the Bermuda-Azores high-pressure system during summer. This prevents frontal systems from passing through the area compared to the winter period, when the high-pressure system is weaker and frontal systems are able to move across Bermuda (Huang et al., 1999; Portis et al., 2001). As different weather systems dominate the isotopic variability during different seasons, we used a wavelet coherence analysis to characterize the relationship between d-excess and $\mathrm{RH}_{\mathrm{SST}}$ in the frequency and time domain (not shown). It confirms that $\mathrm{d}$-excess and $\mathrm{RH}_{\mathrm{SST}}$ time series are strongly anti-correlated over the full data period on timescales of $\sim 1-2$ days up to 2 months (the length of data set does not allow this analysis to be extended on longer timescales). The lack in correlation on timescales below 1-2 days may be due to the analytical limitation, and the too-low signal-to-noise ratio of our d-excess measurements.

Due to the strong anti-correlation between d-excess and $\mathrm{RH}_{\text {SST }}$ on timescales of days to months, it is possible to investigate the relation between d-excess and $\mathrm{RH}_{\mathrm{SST}}$ for different averaging timescales. We divide the record into separate non-overlapping periods ranging from one day up to one month. The estimated slope of the daily to monthly averaged d-excess vs. $\mathrm{RH}_{\mathrm{SST}}$ values is shown in Fig. 12 as a function of the averaging period. We find that the slope for d-excess vs. $\mathrm{RH}_{\text {SST }}$ changes from $\sim-43.6 \pm 0.7\left(R^{2}=0.86, n=494\right)$ to $\sim-52.0 \pm 3.3 \%$ o $\%\left(R^{2}=0.86, n=36\right)$ when increasing the averaging time from 1 day to 2 weeks. Increasing the averaging time from 2 weeks to 1 month does not significantly affect this slope further. We note that time averaging allows for integration across synoptic systems. This is comparable to a spatial averaging across air masses in the region around the Bermuda Islands. While the daily slope is consistent with that of MJ79, increasing averaging time causes the slope to deviate from the theoretical slope of MJ79 and to become closer to the value found by Uemura et al. (2008) from their transect across the Southern Ocean. As the theoretical slope of MJ79 is based on the closure assumption, we hypothesize that the deviation from this slope with increased averaging time (averaging across synoptic systems) reflect that this assumption is no longer valid. Further studies are required to support this hypothesis. Future comparisons between observations and results from atmospheric general circulation models should clearly include the analysis of the relationship between d-excess and $\mathrm{RH}_{\mathrm{SST}}$ along different frequencies, as shown in Fig. 12.

\subsection{Influence of wind direction on d-excess}

In previous sections, we have reported several findings which suggest that changes in moisture advection (and moisture sources) might affect the variability of the d-excess measured in Bermuda. Figure 13 depicts the distribution of d-excess (contours) as a function of relative humidity ( $x$ axis) and wind direction ( $y$ axis), for summer (upper panel) and winter (lower panel), and the differences in relationships between $\mathrm{d}$ excess and $\mathrm{RH}_{\mathrm{SST}}$ for subsets based on specific sectors (subjectively defined) of wind direction. In summer, we find that the d-excess vs. $\mathrm{RH}_{\mathrm{SST}}$ obtained during wind from the western sector has a very negative slope of $-56.7 \pm 2.2 \%$ o $\%$. We conclude that westerly winds cause high summer dexcess levels, possibly due to high kinetic effect induced by warm, dry air masses coming off the American continent (Pfahl and Sodemann, 2014; Gat et al., 2003). In winter, differences in slopes are also identified for specific wind sectors, the southwestern sector (wind directions 200-250 ) leading to the most negative slope and the highest d-excess levels for a given $\mathrm{RH}_{\mathrm{SST}}$ (Table 2). The dependency of the slope of d-excess vs. $\mathrm{RH}_{\mathrm{SST}}$ against wind direction illustrates the limitation of the closure assumption and the need for long-term monitoring in order to deduce the drivers of the d-excess in the marine boundary layer.

\section{Conclusions}

In order to monitor the drivers of marine boundary layer dexcess of the subtropical North Atlantic, we have presented continuous long-term observations of surface water vapor isotopic composition over a $\sim 1.5 \mathrm{yr}$ period between November 2011 and June 2013 from the Bermuda Islands. Thanks to meticulous independent calibration protocols, the intercomparison of two parallel analyzers shows that the accuracy and precision of $10 \mathrm{~min}$ averages of $\delta^{18} \mathrm{O}, \delta D$, and d-excess are, respectively, $0.14,0.85$, and $1.1 \%$. Tests on our monitoring system show that isotopic signals can be accurately retrieved with a temporal resolution down to 1 min intervals. Parallel measurements recorded over a few days by separated water vapor isotope analyzers on each end of the Bermuda Islands show a common signal within these $20 \mathrm{~km}$, suggesting 


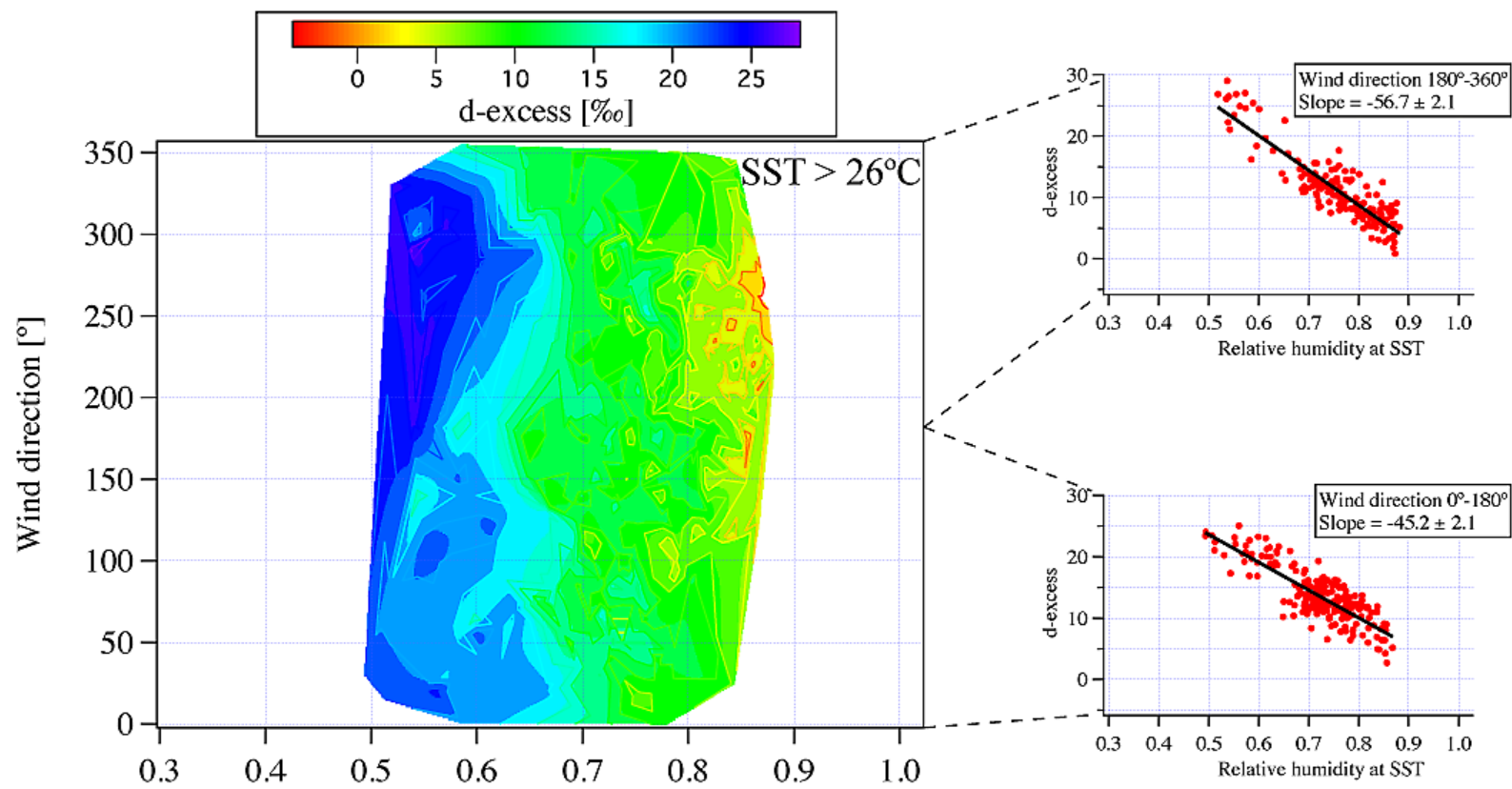

Relative humidity at SST

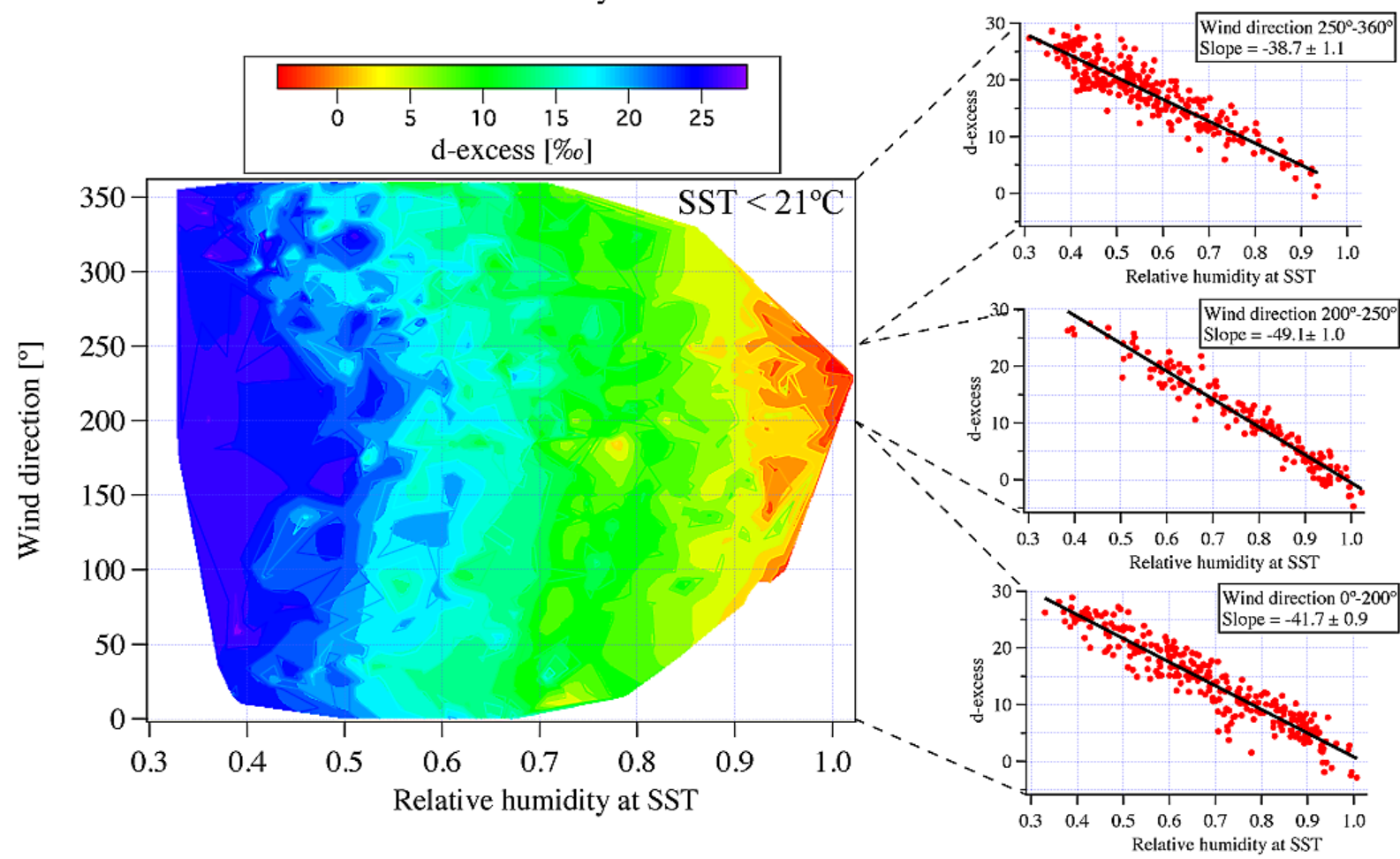

Figure 13. d-excess as a function of wind direction and relative humidity for the summer period (SST $>26^{\circ} \mathrm{C}$ ) (upper panel) and for the winter period $\left(\mathrm{SST}<21^{\circ} \mathrm{C}\right)$ (lower panel).

limited effect of the island. We conclude that the signal is dominated by the marine boundary layer moisture.

The accuracy and precision of the d-excess measurements allow us to document and investigate the controls on the dexcess variability. In accordance with theory, d-excess variability is driven by the relative humidity of the air at the sea surface temperature. However, we could not identify any shifts in relationship with wind speed. In Bermuda, the relationship between d-excess and relative humidity depends on the season, and thereby SST. Moreover, specific wind directions (western winds in summer and southwestern winds in winter) lead to unusually high d-excess values for 
a given humidity level, and a higher negative slope between d-excess and humidity. This feature stresses the limitation of the closure assumption and calls for long-term monitoring in order to characterize the complete set of processes controlling the variability of surface moisture d-excess. Such longterm monitoring indeed allows to evidence processes other than relative humidity (e.g., SST, wind direction), which act on d-excess. We have clearly demonstrated the change of dexcess vs. relative humidity slope as a function of the averaging period (from 1 day to 2 months). Extending our record in time will allow for the investigation of the drivers of dexcess at the inter-annual scale. A next step will be to diagnose changes in moisture source and remote evaporation conditions, using back-trajectory calculations and water tagging within atmospheric models in order to take into account the advection effects highlighted by the impact of wind directions. Our data set will in the future be used to test the validity of deuterium retrievals based on remote sensing (Lacour et al., 2012), and to benchmark atmospheric general circulation models equipped with water-stable isotopes (Werner et al., 2011; Risi et al., 2010; Yoshimura et al., 2008).

\section{The Supplement related to this article is available online at doi:10.5194/acp-14-7741-2014-supplement.}

Acknowledgements. The work was supported by the Danish Council for Independent Research - Natural Sciences grant number 10-092850; the Carlsberg Foundation; the Icelandic Centre for Research - Equipment Fund grant number 1202340031; the Eugene \& Lillian Y Lehman Fellowship at BIOS; CIRES Visiting Fellowship program: and the AXA Research Fund. Operation of the Tudor Hill facility is supported by NSF OCE-1130395. This paper represents BIOS contribution number 2036. Analyses and visualizations used in this paper were produced with the Giovanni online data system, developed and maintained by the NASA GES DISC. We also acknowledge the MODIS mission scientists and associated NASA personnel for the production of the data used in this research effort. We thank the three anonymous referees and the editor Y. Balkanski very much for the constructive and good comments during the review process.

Edited by: Y. Balkanski

\section{References}

Acker, J. G. and Leptoukh, G.: Online analysis enhances use of nasa earth science data, EOS T. Am. Geophys. Un., 88, 14-17, doi:10.1029/2007eo020003, 2007.

Baer, D. S., Paul, J. B., Gupta, M., and O'Keefe, A.: Sensitive absorption measurements in the near-infrared region using off-axis integrated-cavity-output spectroscopy, Appl. Phys. B-Lasers O., 75, 261-265, doi:10.1007/s00340-002-0971-z, 2002.
Bastrikov, V., Steen-Larsen, H. C., Masson-Delmotte, V., Gribanov, K., Cattani, O., Jouzel, J., and Zakharov, V.: Continuous measurements of atmospheric water vapour isotopes in western Siberia (Kourovka), Atmos. Meas. Tech., 7, 1763-1776, doi:10.5194/amt-7-1763-2014, 2014.

Benetti, M., Reverdin, G., Pierre, C., Merlivat, L., Risi, C., SteenLarsen, H. C., and Vimeux, F.: Deuterium excess in marine water vapor: dependency on relative humidity and surface wind speed during evaporation, J. Geophys. Res.-Atmos., 119, 584593, doi:10.1002/2013JD020535, 2014.

Bonne, J.-L., Masson-Delmotte, V., Cattani, O., Delmotte, M., Risi, C., Sodemann, H., and Steen-Larsen, H. C.: The isotopic composition of water vapour and precipitation in Ivittuut, southern Greenland, Atmos. Chem. Phys., 14, 4419-4439, doi:10.5194/acp-14-4419-2014, 2014.

Berkelhammer, M., Hu, J., Bailey, A., Noone, D. C., Still, C. J., Barnard, H., Gochis, D., Hsiao, G. S., Rahn, T., and Turnipseed, A.: The nocturnal water cycle in an opencanopy forest, J. Geophys. Res.-Atmos., 118, 10225-10242, doi:10.1002/jgrd.50701, 2013.

Brutsaert, W.: A theory for local evaporation (or heat transfer) from rough and smooth surfaces at ground level, Water Resour. Res., 11, 543-550, doi:10.1029/WR011i004p00543, 1975.

Craig, H.: Standard for reporting concentrations of deuterium and oxygen-18 in natural waters, Science, 133, 1833-1834, doi:10.1126/science.133.3467.1833, 1961a.

Craig, H.: Isotopic variations in meteoric waters, Science, 133, 1702-1703, $1961 b$.

Craig, H. and Gordon, L. I.: Deuterium and oxygen 18 variations in the ocean and the marine atmosphere, in: Stable Isotopes in Oceanographic Studies and Paleotemperatures, 26-30 July 1965, Spoleto, Italy, 1965.

Crosson, E. R., Ricci, K. N., Richman, B. A., Chilese, F. C., Owano, T. G., Provencal, R. A., Todd, M. W., Glasser, J., Kachanov, A. A., Paldus, B. A., Spence, T. G., and Zare, R. N.: Stable isotope ratios using cavity ring-down spectroscopy: determination of C-13/C-12 for carbon dioxide in human breath, Anal. Chem., 74, 2003-2007, doi:10.1021/ac025511d, 2002.

Dansgaard, W.: The $\mathrm{O}^{18}$-abundance in fresh water, Geochim. Cosmochim. Ac., 6, 241-260, 1954.

Dansgaard, W.: Stable isotopes in precipitation, Tellus, 16, 436468, 1964.

Ellehoj, M. D., Steen-Larsen, H. C., Johnsen, S. J., and Madsen, M. B.: Ice-vapor equilibrium fractionation factor of hydrogen and oxygen isotopes: Experimental investigations and implications for stable water isotope studies, Rapid Commun. Mass Sp., 27, 2149-2158, doi:10.1002/rcm.6668, 2013.

Epstein, S. and Mayeda, T.: Variation of the 18-o content of waters from natural sources, Geochim. Cosmochim. Ac., 4, 213-224, 1953.

Fisher, D. A.: Stable isotope simulations using a regional stable isotope model coupled to a zonally averaged global model, Cold Reg. Sci. Technol., 21, 61-77, 1992.

Gat, J. R., Klein, B., Kushnir, Y., Roether, W., Wernli, H., Yam, R., and Shemesh, A.: Isotope composition of air moisture over the mediterranean sea: an index of the air-sea interaction pattern, Tellus B, 55, 953-965, 2003.

Haines, S. L., Jedlovec, G. J., and Lazarus, S. M.: A modis sea surface temperature composite for regional applications, IEEE T. 
Geosci. Remote, 45, 2919-2927, doi:10.1109/tgrs.2007.898274, 2007.

Huang, S., Rahn, K. A., Arimoto, R., Graustein, W. C., and Turekian, K. K.: Semiannual cycles of pollution at bermuda, J. Geophys. Res.-Atmos., 104, 30309-30317, doi:10.1029/1999jd900801, 1999.

Johnsen, S. J.: Stable isotope homogenization of polar firn and ice. Proc. of Symp. on Isotopes and Impurities in Snow and Ice, i. U. G. G. XVI, general assembly, Grenoble, August-September 1975, IAHS-AISH P., 118, 210-219, 1977.

Johnsen, S. J., Dansgaard, W., and White, J. W. C.: The origin of arctic precipitation under present and glacial conditions, Tellus B, 41, 452-468, 1989.

Johnsen, S. J., Clausen, H. B., Cuffey, K. M., Hoffmann, G., Schwander, J., and Creyts, T.: Diffusion of stable isotopes in polar firn and ice: the isotope effect in firn diffusion, in: Physics of Ice Core Records, edited by: Hondoh, T., Hokkaido University Press, Sapporo, 121-140, 2000.

Jouzel, J., Alley, R. B., Cuffey, K. M., Dansgaard, W., Grootes, P., Hoffmann, G., Johnsen, S. J., Koster, R. D., Peel, D., Shuman, C. A., Stievenard, M., Stuiver, M., and White, J.: Validity of the temperature reconstruction from water isotopes in ice cores, J. Geophys. Res., 102, 26471-26487, 1997.

Jouzel, J., Stiévenard, M., Johnsen, S. J., Landais, A., Masson-Delmotte, V., Sveinbjornsdottir, A., Vimeux, F., von Grafenstein, U., and White, J. W. C.: The GRIP deuterium-excess record, Quaternary Sci. Rev., 26, 1-17, doi:10.1016/j.quascirev.2006.07.015, 2007.

Kurita, N.: Origin of arctic water vapor during the icegrowth season, Geophys. Res. Lett., 38, L02709, doi:10.1029/2010g1046064, 2011.

Lacour, J.-L., Risi, C., Clarisse, L., Bony, S., Hurtmans, D., Clerbaux, C., and Coheur, P.-F.: Mid-tropospheric $\delta D$ observations from IASI/MetOp at high spatial and temporal resolution, Atmos. Chem. Phys., 12, 10817-10832, doi:10.5194/acp12-10817-2012, 2012.

Majoube, M.: Fractionnement en oxygène 18 et en deutérium entre l'eau et sa vapeur, J. Climate Phys., 68, 1423-1436, 1971.

Massman, W. J. and Ibrom, A.: Attenuation of concentration fluctuations of water vapor and other trace gases in turbulent tube flow, Atmos. Chem. Phys., 8, 6245-6259, doi:10.5194/acp-86245-2008, 2008.

Masson-Delmotte, V., Landais, A., Stievenard, M., Cattani, O., Falourd, S., Jouzel, J., Johnsen, S. J., Dahl-Jensen, D., Sveinbjornsdottir, A., White, J. W. C., Popp, T., and Fisher, H.: Holocene climatic changes in greenland: different deuterium excess signals at greenland ice core project (grip) and northgrip, J. Geophys. Res., 110, D14102, doi:10.1029/12004JD005575, 2005.

Merlivat, L. and Jouzel, J.: Global climatic interpretation of the deuterium-oxygen 18 relationship for precipitation, J. Geophys. Res., 84, 5029-5033, 1979.

Pfahl, S. and Sodemann, H.: What controls deuterium excess in global precipitation?, Clim. Past, 10, 771-781, doi:10.5194/cp10-771-2014, 2014.

Pfahl, S. and Wernli, H.: Lagrangian simulations of stable isotopes in water vapor - an evaluation of non-equilibrium fractionation in the Craig-Gordon model, J. Geophys. Res., 114, D20108, doi:10.1029/2009JD012054, 2009
Portis, D. H., Walsh, J. E., El Hamly, M., and Lamb, P. J.: Seasonality of the north atlantic oscillation, J. Climate, 14, 2069-2078, doi:10.1175/1520-0442(2001)012.0.CO;2, 2001.

Risi, C., Bony, S., Vimeux, F., and Jouzel, J.: Water stable isotopes in the $1 \mathrm{mdz} 4$ general circulation model: model evaluation for present day and past climates and applications to climatic interpretations of tropical isotopic records, J. Geophys. Res., 115, D12118, doi:10.1029/2009JD013255, 2010.

Rozanski, K., Araguás-Araguás, L., and Gonfiantini, R.: Isotopic patterns in modern global precipitation, in: Climate Change in Continental Isotopic Records, Geophys. Monogr. Ser. Vol. 78, American Geophysical Union (AGU), Washington, DC, 1-36, 1993.

Spank, U. and Bernhofer, C.: Another simple method of spectral correction to obtain robust Eddy-covariance, Bound.-Lay. Meteorol., 128, 403-422, doi:10.1007/s10546-008-9295-9, 2008.

Steen-Larsen, H. C., Masson-Delmotte, V., Sjolte, J., Johnsen, S. J., Vinther, B. M., Breon, F. M., Clausen, H. B., Dahl-Jensen, D., Falourd, S., Fettweis, X., Gallee, H., Jouzel, J., Kageyama, M., Lerche, H., Minster, B., Picard, G., Punge, H. J., Risi, C., Salas, D., Schwander, J., Steffen, K., Sveinbjornsdottir, A. E., Svensson, A., and White, J.: Understanding the climatic signal in the water stable isotope records from the neem shallow firn/ice cores in northwest greenland, J. Geophys. Res.-Atmos., 116, D06108, doi:10.1029/2010jd014311, 2011.

Steen-Larsen, H. C., Johnsen, S. J., Masson-Delmotte, V., Stenni, B., Risi, C., Sodemann, H., Balslev-Clausen, D., Blunier, T., Dahl-Jensen, D., Ellehoj, M. D., Falourd, S., Grindsted, A., Gkinis, V., Jouzel, J., Popp, T., Sheldon, S., Simonsen, S. B., Sjolte, J., Steffensen, J. P., Sperlich, P., Sveinbjörnsdóttir, A. E., Vinther, B. M., and White, J. W. C.: Continuous monitoring of summer surface water vapor isotopic composition above the Greenland Ice Sheet, Atmos. Chem. Phys., 13, 48154828, doi:10.5194/acp-13-4815-2013, 2013.

Steen-Larsen, H. C., Masson-Delmotte, V., Hirabayashi, M., Winkler, R., Satow, K., Prié, F., Bayou, N., Brun, E., Cuffey, K. M., Dahl-Jensen, D., Dumont, M., Guillevic, M., Kipfstuhl, S., Landais, A., Popp, T., Risi, C., Steffen, K., Stenni, B., and Sveinbjörnsdottír, A. E.: What controls the isotopic composition of Greenland surface snow?, Clim. Past, 10, 377-392, doi:10.5194/cp-10-377-2014, 2014.

Tremoy, G., Vimeux, F., Mayaki, S., Souley, I., Cattani, O., Risi, C., Favreau, G., and Oi, M.: A 1 yr long $\delta^{18} \mathrm{O}$ record of water vapor in Niamey (Niger) reveals insightful atmospheric processes at different timescales, Geophys. Res. Lett., 39, L08805, doi:10.1029/2012GL051298, 2012.

Uemura, R., Matsui, Y., Yoshimura, K., Motoyama, H., and Yoshida, N.: Evidence of deuterium excess in water vapor as an indicator of ocean surface conditions, J. Geophys. Res.-Atmos., 113, D19114, doi:10.1029/2008jd010209, 2008.

Welp, L. R., Lee, X., Griffis, T. J., Wen, X.-F., Xiao, W., Li, S., Sun, X., Hu, Z., Val Martin, M., and Huang, J.: A metaanalysis of water vapor deuterium-excess in the midlatitude atmospheric surface layer, Global Biogeochem. Cy., 26, GB3021, doi:10.1029/2011gb004246, 2012.

Werner, M., Langebroek, P. M., Carlsen, T., Herold, M., and Lohmann, G.: Stable water isotopes in the echam5 general circulation model: toward high-resolution isotope modeling 
on a global scale, J. Geophys. Res.-Atmos., 116, D15109, doi:10.1029/2011jd015681, 2011.
Yoshimura, K., Kanamitsu, M., Noone, D., and Oki, T.: Historical isotope simulation using reanalysis atmospheric data, J. Geophys. Res.-Atmos., 113, D19108, doi:10.1029/2008jd010074, 2008. 